\title{
The Role of Wave Dynamics and Small-Scale Topography for Downslope Wind Events in Southeast Greenland
}

\author{
M. Oltmanns, F. StraneO, And H. SeO \\ Woods Hole Oceanographic Institution, Woods Hole, Massachusetts \\ G. W. K. MOORE \\ University of Toronto, Toronto, Ontario, Canada
}

(Manuscript received 4 September 2014, in final form 1 April 2015)

\begin{abstract}
In Ammassalik, in southeast Greenland, downslope winds can reach hurricane intensity and represent a hazard for the local population and environment. They advect cold air down the ice sheet and over the Irminger Sea, where they drive large ocean-atmosphere heat fluxes over an important ocean convection region. Earlier studies have found them to be associated with a strong katabatic acceleration over the steep coastal slopes, flow convergence inside the valley of Ammassalik, and-in one instance-mountain wave breaking. Yet, for the general occurrence of strong downslope wind events, the importance of mesoscale processes is largely unknown. Here, two wind events-one weak and one strong-are simulated with the atmospheric Weather Research and Forecasting (WRF) Model with different model and topography resolutions, ranging from 1.67 to $60 \mathrm{~km}$. For both events, but especially for the strong one, it is found that lower resolutions underestimate the wind speed because they misrepresent the steepness of the topography and do not account for the underlying wave dynamics. If a $5-\mathrm{km}$ model instead of a $60-\mathrm{km}$ model resolution in Ammassalik is used, the flow associated with the strong wind event is faster by up to $20 \mathrm{~m} \mathrm{~s}^{-1}$. The effects extend far downstream over the Irminger Sea, resulting in a diverging spatial distribution and temporal evolution of the heat fluxes. Local differences in the heat fluxes amount to $20 \%$, with potential implications for ocean convection.
\end{abstract}

\section{Introduction}

Downslope winds in southeast Greenland can reach hurricane intensity, posing a threat to the local population (Rasmussen 1989; Born and Böcher 2000; Klein and Heinemann 2002; Heinemann and Klein 2002; Mernild et al. 2008). They are especially pronounced within the valley of Ammassalik, where the flow is funneled by the topography (Figs. 1 and 5). Using the European Centre for Medium-Range Weather Forecasts (ECMWF) interim reanalysis (ERA-I), Oltmanns et al. (2014) constructed a composite of strong downslope wind events (DWE). There were seven events per year on average, reaching surface wind speeds of about $20 \mathrm{~m} \mathrm{~s}^{-1}$. The downslope winds are supported by a synoptic-scale cyclone such that

Corresponding author address: M. Oltmanns, Physical Oceanography Department, Woods Hole Oceanographic Institution, 266 Woods Hole Road, Woods Hole, MA 02543.

E-mail: marilena@mit.edu the geostrophic flow is in approximately the same direction as the local topographic gradient. They advect cold air from the ice sheet down the steep coastal topography, and, thus, they have a strong katabatic component. In fact, temperatures of $-20^{\circ} \mathrm{C}$ have been recorded in Ammassalik during an extremely intense DWE with estimated wind speeds of $90 \mathrm{~m} \mathrm{~s}^{-1}$ (Rasmussen 1989; Born and Böcher 2000).

DWE are not only a hazard for the local population and environment; they can also influence the coastal and regional ocean, which has implications for global climate. The cold and strong winds drive large heat fluxes downstream over the Irminger Sea (Oltmanns et al. 2014) near an important ocean convection region (Pickart et al. 2003; Vage 2010). Thus, DWE could precondition or initiate convection and thereby affect the meridional overturning circulation (Jungclaus et al. 2005; Stouffer et al. 2006), the climate of northwest Europe (Vellinga and Wood 2002), and the sequestration of carbon dioxide by the deep ocean (Sabine et al. 2004). Moreover, DWE were found 
to advect sea ice offshore (Oltmanns et al. 2014), with possible consequences for the local outlet glacier (Amundson et al. 2010; Howat et al. 2010; Walter et al. 2012) and coastal ecology (Grebmeier et al. 1995).

Compared with local weather stations, ERA-I underestimated the wind speed of DWE in the composite analysis (Oltmanns et al. 2014), never reaching the hurricane intensity that is sometimes observed in the local town (Rasmussen 1989; Born and Böcher 2000; Mernild et al. 2008). This suggests that the reanalysis does not resolve the full dynamics underlying these wind events. The notion that a higher model resolution is necessary to accurately simulate wind speed is in line with previous studies of tip jets and barrier winds in southeast Greenland (DuVivier and Cassano 2013). In the case of DWE, there already exists a fast downslope flow in ERA-I because of a strong large-scale, synoptic pressure gradient and gravitational acceleration, as well as flow convergence in the larger-scale Ammassalik valley (Oltmanns et al. 2014). It remains to be determined which smaller-scale dynamics the ERA-I does not resolve.

One possible mechanism by which downslope winds can be extremely accelerated is by mountain waves (Smith 1985; Durran 1986; Bacmeister and Pierrehumbert 1988). These develop when stratified air is forced over a topographic barrier. According to the Eliassen-Palm theorem, mountain waves are associated with a downward momentum flux that is transferred to the topography by the cross-mountain pressure drag (Eliassen and Palm 1961; Durran 2003). When they attain sufficiently large amplitude, they can break and overturn. This results in a strongly divergent momentum flux profile such that there is a significant deceleration of the mean flow in the wave-breaking region and acceleration of the downslope flow below. Indeed, during one DWE in Ammassalik, dropwindsondes and aircraft measurements depict the breaking of a largeamplitude mountain wave (Doyle et al. 2005). While ERA-I did reproduce this wind event, it did not resolve the mountain wave. This suggests that model resolution affects the ability to resolve some of the leading-order dynamics and thereby influences the magnitude of the simulated wind speed.

Mountain waves and mountain wave breaking are not only associated with downslope wind storms but can influence atmospheric dynamics on many scales, including the general atmospheric circulation and climate (Fritts and Alexander 2003). The effects of wave drag and fluxes on the momentum balance play an important role in determining the structure of the large-scale flow in the troposphere and lower stratosphere (McFarlane 1987). Furthermore, the large vertical momentum fluxes and turbulence facilitate the vertical mixing of water vapor, aerosols, and chemical species (Dörnbrack and
Dürbeck 1998), thus affecting the chemical properties of the atmosphere. In addition, the clear-air turbulence that develops in regions of mountain wave breaking represents a significant hazard to aviation (Ralph et al. 1997; Clark et al. 2000). Encounters of aircraft turbulence were also associated with mountain waves over west Greenland (Lane et al. 2009). Yet there has been no study connecting mountain waves and mountain wave breaking with the general occurrence of DWE in Ammassalik.

Physically, mountain wave-induced wind storms can be understood in terms of hydraulic theory. On the upstream side of the mountain, the flow is accelerated because of the pressure gradient acceleration associated with the mountain wave. When the wave breaks on the downslope side of the mountain, a hydraulic jump-like phenomenon occurs, and the flow transitions from a wave-dominant (or subcritical) regime to a supercritical regime. In the supercritical regime, the flow is further accelerated by the gravitational acceleration (Durran 1990). In hydraulic theory, the Froude number describes the regime of a fluid: $\operatorname{Fr}=u(g D)^{-1 / 2}$, with depth $D$, velocity $u$, and gravitational acceleration $g$. Froude numbers above (below) 1 correspond to the supercritical (subcritical) regime. For a continuously stratified atmosphere, a Froude number analog $\left[\mathrm{Fr}=u(N H)^{-1}\right]$ is often defined to classify atmospheric flows. In this case, $H$ is the mountain height, $N$ is the Brunt-Väisälä frequency, and $u$ is a suitably defined upstream wind speed.

Mountain waves and gravity flows are not independent phenomena, as they can interact with each other. Based on idealized simulations, Poulos et al. (2000) find that radiative cooling can enhance the mountain wave flow speed in the lee for Froude numbers up to 0.75. For Froude numbers above approximately 0.5 , the gravity current can be scoured such that the mountain wave flow penetrates to the surface, while for Froude numbers less than approximately 0.5 , the katabatic flow and the mountain wave couple, resulting in a complex mutually interdependent evolution (Poulos et al. 2000, 2007). While mountain waves can influence the intensity, depth, and local variability of katabatic winds through turbulence and dynamic pressure perturbations (Mursch-Radlgruber 1995; Jin et al. 1996; Poulos et al. 2000), the stability and reduced turbulence of a lower stratified layer can, in turn, affect the dynamics of mountain waves (Scorer 1967; Poulos et al. 2000). Thus, the effects of potentially unresolved mountain wave processes in ERA-I during DWE could amplify through interactions with the gravity current.

In this study, we investigate the role played by processes that are unresolved by the 80-km grid spacing of the ERA-I and how they interact with other terms in the momentum balance. Specifically, we simulate two DWE-one weak 
and one strong-with the Weather Research and Forecasting (WRF) Model using different model and topography resolutions to study the small-scale dynamics in Ammassalik and their effects on larger scales. Here, and in the following, we use the term "small scale" to characterize processes that are resolved using a grid spacing between 5 and $20 \mathrm{~km}$. In numerical models, the energy in the highest resolved wavenumbers tends to be overly damped. Therefore, the model's effective resolution is defined as the scale at which the model's kinetic energy spectrum decays relative to the observed spectrum (Skamarock 2004). Previous stimulations with the WRF Model have shown that the effective resolution is about 7 times the grid spacing (Skamarock 2004); thus, we expect a model with a grid spacing of $5(60) \mathrm{km}$ to resolve processes on scales of $35(420) \mathrm{km}$, which lie within the meso- $\beta$ (meso $\alpha$ ) scale (Orlanski 1975).

The analysis is separated into four parts. First, we describe the characteristics of the two wind events and investigate how they are represented by different model resolutions. In the second part, we study the dynamics by comparing individual driving forces in the momentum balance and assess the role played by small-scale momentum fluxes. We also consider the case in which the model is run at high resolution but with a smoothed topography. Our results indicate that the lower resolutions underestimate the wind speed, because they do not account for the underlying wave dynamics that contribute to accelerate the downslope flow. When the topography is smoothed, the cross-mountain pressure drag associated with the mountain wave is reduced, resulting in a smaller downward momentum flux and overall lower wind speeds, even if the model resolution is unchanged. In the third part, we analyze interactions between the mountain wave and the gravitational acceleration and study how they are affected by model resolution. Finally, we look at the evolution of the downslope flow and investigate what the impact of using a higher model resolution for the downslope wind events is on the larger scales of motions. We find that the downstream wind field is affected by small-scale processes within the Ammassalik valley. The effects extend farther out over the Irminger Sea with consequences for the distribution and magnitude of the ocean-atmosphere heat fluxes and thus, potentially, ocean convection.

\section{Data and methods}

To compare the effect of using different resolutions, we simulate two wind events with the WRF Model (version 3.5) (Michalakes et al. 2004; Skamarock et al. 2008), one of which is weak and the other is one strong compared with the composite of DWE described in
Oltmanns et al. (2014). The wind events, also seen by local weather stations, were mainly identified with a condition of wind speed. Both events are associated with a wind and sea level pressure field with a general structure that is representative of the composite. The strong wind event occurred on 3 February 1999, with maximum surface wind speeds of $28 \mathrm{~m} \mathrm{~s}^{-1}$ at 1800 UTC in ERA-I; and the weak one occurred on 9 April 2007, with maximum surface wind speeds of $21 \mathrm{~m} \mathrm{~s}^{-1}$ at 0600 UTC in ERA-I (Fig. 1). ERA-I obtained these wind speeds inside the valley of Ammassalik near the coast but not directly at the weather station location, where wind speeds of 32.5 and $16.5 \mathrm{~m} \mathrm{~s}^{-1}$ were observed during the strong and weak wind events, respectively (see Fig. 1 for station location). Both wind events are simulated on a $60-\mathrm{km}$-resolution domain (WRF60) with two nests-one with 20-km resolution (WRF20) and one with 5-km resolution (WRF5) leaving all other model parameters unchanged (Fig. 1).

We run three simulations. In the first case, we use oneway nesting, which allows us to compare the effect of using four different resolutions within the innermost domain boundaries. In the second case, we use two-way nesting such that feedbacks from the WRF5 and WRF20 domains are allowed. In the third case, the nesting is again one-way, and we use topography with a resolution of $60 \mathrm{~km}$ also in the WRF5 and WRF20 domains. It is obtained by linearly interpolating the $60-\mathrm{km}$-resolution topography in WRF60 to the additional grid points in the 20- and 5-km domains. In each simulation, we use 30 vertical sigma levels, the highest being at $50 \mathrm{hPa}$. The level distribution (shown in Fig. 3) is surface intensified to yield a good vertical resolution near the surface. Physics parameterizations are specified in Table 1 . They were chosen based on current knowledge of their efficiency and accuracy, as well as their suitability under snow and ice conditions (Janjić et al. 2011). The simulations are run for $24 \mathrm{~h}$, starting $12 \mathrm{~h}$ before the time of maximum wind speed in ERA-I. ERA-I provides the boundary and initial conditions. Because of the short simulation period of $24 \mathrm{~h}$, the initial conditions are the dominant factor influencing the dynamics, and internal model variability is less important. If we start the simulations $6 \mathrm{~h}$ earlier or use different aspect ratios for the domains, the results do not change appreciably.

As a 5-km horizontal resolution could potentially misrepresent nonhydrostatic waves and alias energy into larger-scale hydrostatic waves (Reinecke and Durran 2009), an additional simulation was carried out with a third nest with a horizontal grid spacing of $1.67 \mathrm{~km}$ (WRF1.7) and 45 vertical levels. Most of the analysis is based on the WRF60 and WRF5 domains. The 1.67-km-resolution domain extends over the central part of the Ammassalik valley and was only used for comparison with the WRF5 
a)

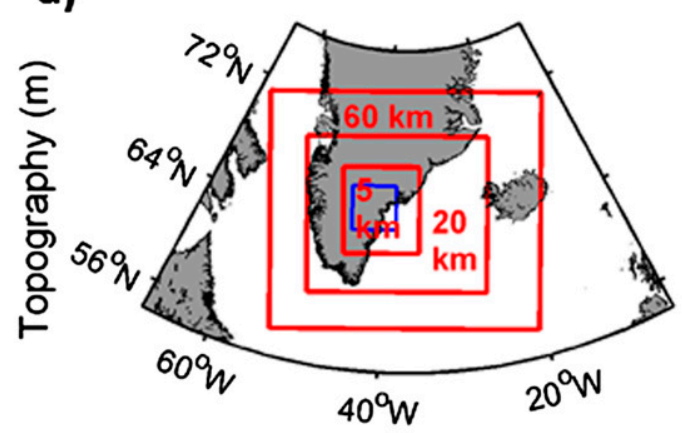

c)

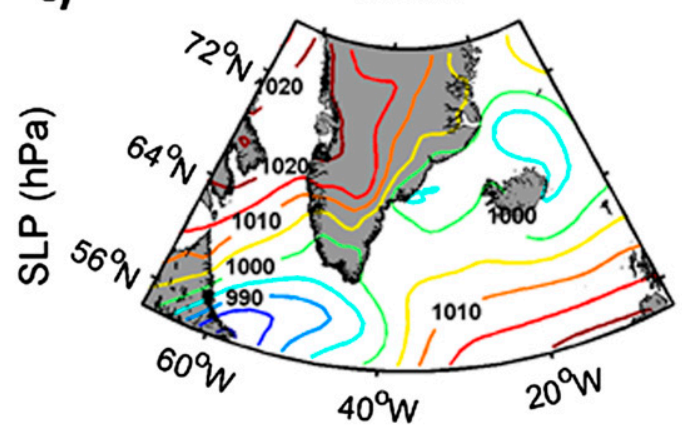

b)

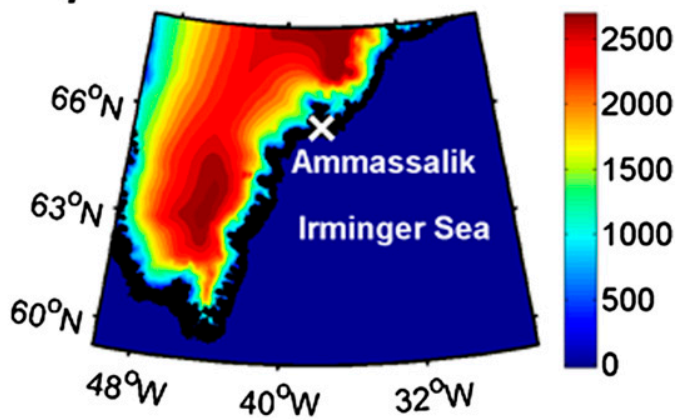

d)

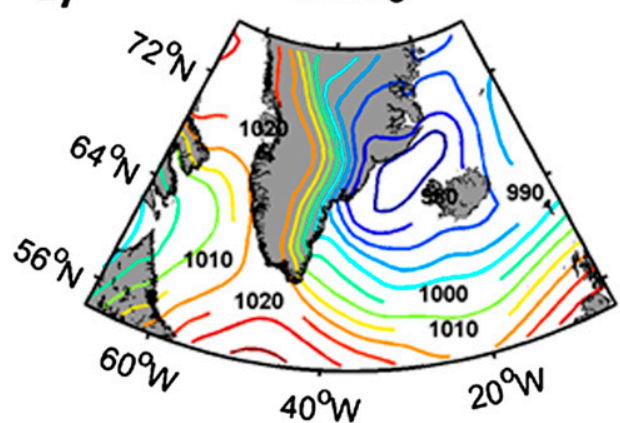

Strong

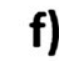

f)

)

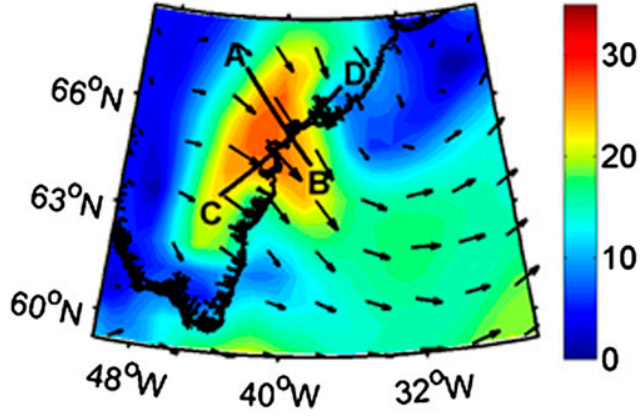

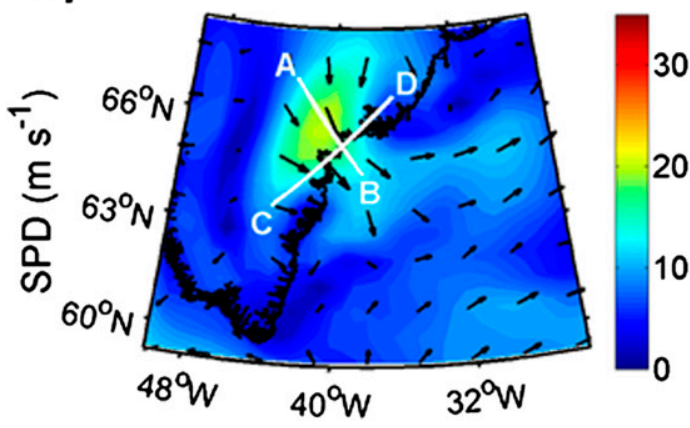

Weak

FIG. 1. (a) WRF simulation domains: the blue line delineates the 1.67-km-resolution domain. (b) Topography $(\mathrm{m})$ in southeast Greenland, including the valley of Ammassalik. The white cross indicates the location of the DMI station; (c),(d) SLP (hPa) and (e),(f) wind speed ( $\mathrm{m} \mathrm{s}^{-1}$ ) for (c),(e) the weak event in ERA-I on 9 Apr 2007 and (d),(f) the strong wind event on 3 Feb 1999. The lines mark the sections shown in Figs. 3 and 4.

domain to assess the importance of smaller-scale nonhydrostatic waves that can be unresolved in WRF5.

ERA-I (Dee et al. 2011) has been used successfully for the study of several wind events in or near the study region (e.g., Harden et al. 2011), including the DWE discussed in this paper (Oltmanns et al. 2014). The data have a 6-hourly temporal resolution, 60 vertical levels in the model's terrain-following vertical coordinates, and a horizontal resolution of approximately $80 \mathrm{~km}$ at the surface. Several studies have compared ERA-I with observations (e.g., dropsondes) in the Irminger Sea and Greenland region with the general conclusion that
ERA-I captures the basic wind and temperature fields but tends to underestimate the magnitude of gradients during high-wind-speed conditions (Renfrew et al. 2008; Harden et al. 2011). Over the Greenland ice sheet, the $10-\mathrm{m}$ wind field agrees with the observations from automated weather stations with root-mean-square errors of about $1 \mathrm{~m} \mathrm{~s}^{-1}$ and correlations of about 0.65 (Moore et al. 2013), and in a study about surface-based inversions in the Arctic, it was found that ERA-I data agreed reasonably well with radiosonde observations (Zhang et al. 2011). A comparison between ERA-I and the 2011 reprocessed QuickSCAT ocean wind vectors 
TABLE 1. WRF Model physics specifications that are used for the three simulations.

\begin{tabular}{|c|c|}
\hline Variable & Scheme \\
\hline Microphysics & $\begin{array}{l}\text { WRF single-moment 3-class } \\
\text { (WSM3; Hong et al. 2004) }\end{array}$ \\
\hline Longwave radiation & $\begin{array}{l}\text { Rapid Radiation Transfer Model } \\
\text { (RRTM; Mlawer et al. 1997) }\end{array}$ \\
\hline Shortwave radiation & Dudhia scheme (Dudhia 1989) \\
\hline Surface layer & $\begin{array}{l}\text { Revised MM5 Monin-Obukhov } \\
\text { scheme (Jiménez et al. 2012) }\end{array}$ \\
\hline Land surface model & $\begin{array}{l}\text { Unified Noah land surface model } \\
\text { (Chen and Dudhia 2001) }\end{array}$ \\
\hline Boundary layer & $\begin{array}{l}\text { Yonsei University (YSU) PBL } \\
\text { scheme (Hong et al. 2006) }\end{array}$ \\
\hline Cumulus parameterization & $\begin{array}{l}\text { Kain-Fritsch cumulus convection } \\
\text { scheme (Kain and Fritsch 1990) }\end{array}$ \\
\hline
\end{tabular}

with an improved geophysical model function (Ricciardulli and Wentz 2011) during DWEs from 2000 to 2009 showed that ERA-I captures the structure of the wind field well but underestimates the wind speeds by about $1-2 \mathrm{~m} \mathrm{~s}^{-1}$ over the ocean in the region of the peak wind speeds (Oltmanns et al. 2014). This is expected, as DWE have a comparably small scale and very high wind speeds, two conditions in which reanalyses often have problems (Renfrew et al. 2009). One potential explanation for the different wind speeds is the coarse resolution of the reanalysis. Thus, in the following, we will investigate how strongly model resolution affects the simulation of DWE.

\section{Results}

\section{a. Characteristics}

To test the influence of model resolution on the wind event characteristics, we first investigate the surface wind field in WRF60, WRF20, and WRF5 in the oneway nesting simulation at the time when they record the maximum wind speed. For this purpose, we determine the location of the maximum wind speed in the three domains, only requiring it to be within the boundaries of WRF5 and north of $64^{\circ} \mathrm{N}$, and analyze the wind speed evolution at this location (Fig. 2). For both events, the location where the maximum wind speed occurs is similar in WRF5, WRF20, and WRF60 (Fig. 2). The higher the resolution is, the closer this location is to the coast. Compared with the lower-resolution domains, WRF5 has a finer structure (Fig. 2). The largest differences are seen near the coast in the southern part of the valley and in the outflow region. The outflow onto the shelf is narrower in WRF5, with two distinct minima in wind speed next to it. Thus, the differences in the obtained wind speed between the domains occur not only over land, where the topographic resolution likely has a strong influence on the surface winds, but are carried downstream over the ocean. The differences are more pronounced for the strong wind event, but they also exist for the weak one.

Next, we compare the evolution of the wind field in the different domains at the location where they obtain the maximum wind speed. For the strong event, WRF5 obtains wind speeds that are about $5 \mathrm{~m} \mathrm{~s}^{-1}$ higher than in WRF20 and about $10 \mathrm{~m} \mathrm{~s}^{-1}$ higher than in WRF60. For the weak wind event, WRF5 also obtains higher wind speeds, but the difference with WRF20 and WRF60 is smaller. The fastest winds reach speeds of $45 \mathrm{~m} \mathrm{~s}^{-1}$ during the strong event and $30 \mathrm{~m} \mathrm{~s}^{-1}$ during the weak event. Also, WRF5 obtains a more rapid initial increase of the wind speed during the strong wind event and a more rapid decrease after the maximum wind speed has been reached. Thus, the wind speed time series in WRF60 has a broader and flatter temporal evolution compared with WRF5, which could be related to both an overall different wind speed evolution and the slight shift in location of maximum wind speed (Fig. 2).

We also compare the surface wind fields between WRF1.7 and WRF5 at the time when WRF5 obtains the maximum wind speed (not shown). Within the WRF1.7 domain, the distribution and magnitude of the surface wind speed is almost identical to WRF5. The largest differences occur at confined locations in the outflow region at the coast and are on the order of $2 \mathrm{~m} \mathrm{~s}^{-1}$ for the strong event and $3 \mathrm{~m} \mathrm{~s}^{-1}$ for the weak event. For both events, the wind speed evolution in WRF1.7 and WRF5 at the location where WRF5 obtains the maximum wind speed agree very well (Fig. 2), and the locations where the maximum wind speeds are obtained are close to each other.

At the location of the Danish Meteorological Institute (DMI) weather station (just outside the WRF1.7 domain; see Fig. 1b or 2 for station location), WRF5 agrees best with the observed wind speed, especially during the strong wind event (Fig. 2). For the weak event, WRF5, WRF20, and WRF60 obtain similar wind speeds. All three domains capture the low-frequency evolution of the wind event but record a faster wind speed drop off than is observed. A possible reason for the discrepancy between the model and the observations is the sharp gradient in the wind speed field near the station location such that a slight variation in the temporal evolution of the front can result in very different wind speeds at the weather station. Other reasons could include inaccuracies in the boundary conditions (despite the fact that the weather station data is assimilated in the reanalysis), errors resulting from the interpolation to the station location, and a misrepresentation of the complex topography in this region. In the following, we will mostly show results from the strong wind event. For the weak event, the winds and its underlying driving forces are reduced, 
a)

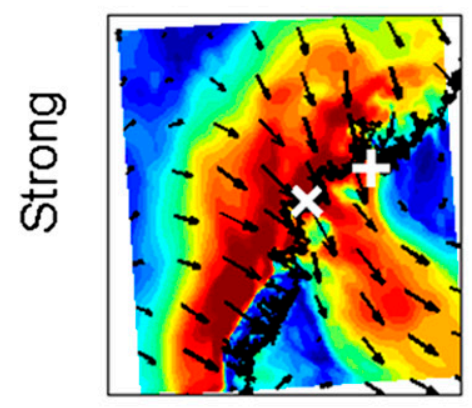

WRF20

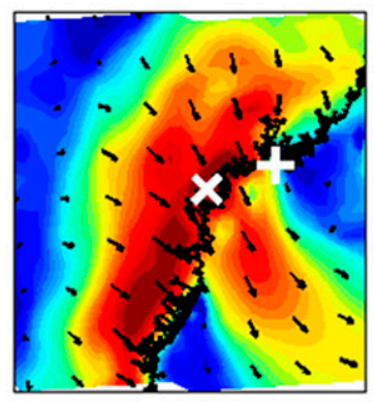

\section{WRF60}
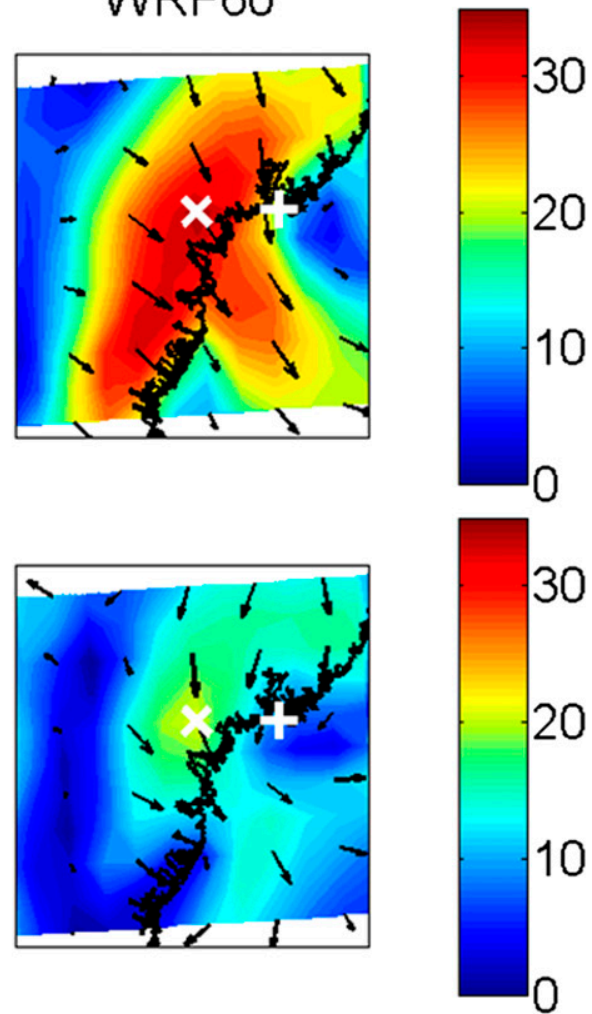

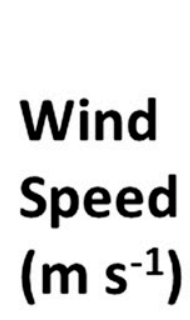

b)

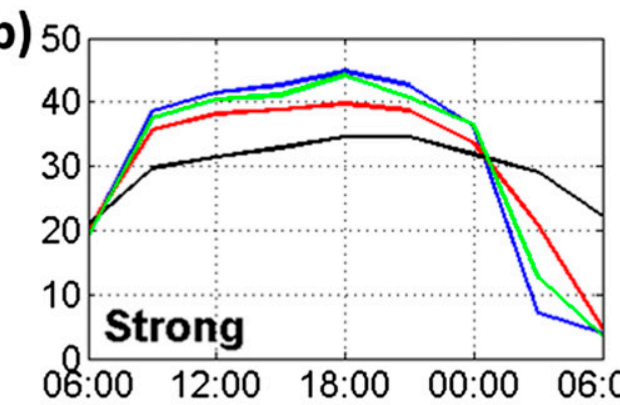

d) 5

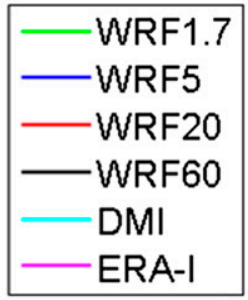

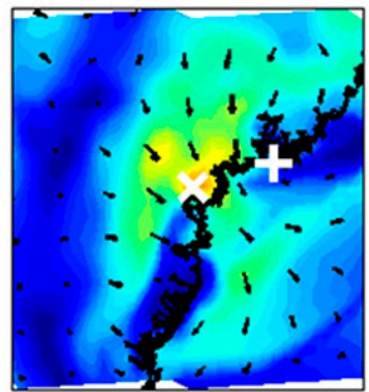

c)

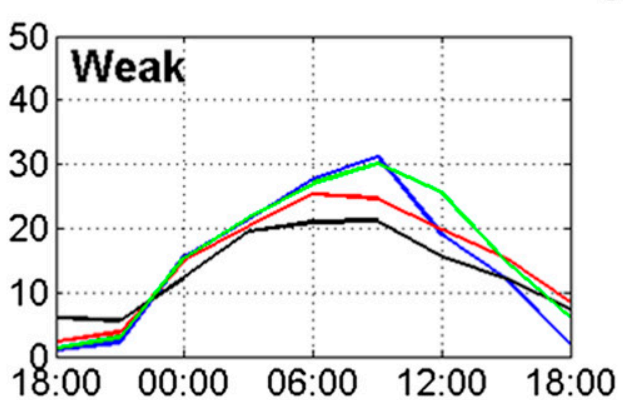

e)

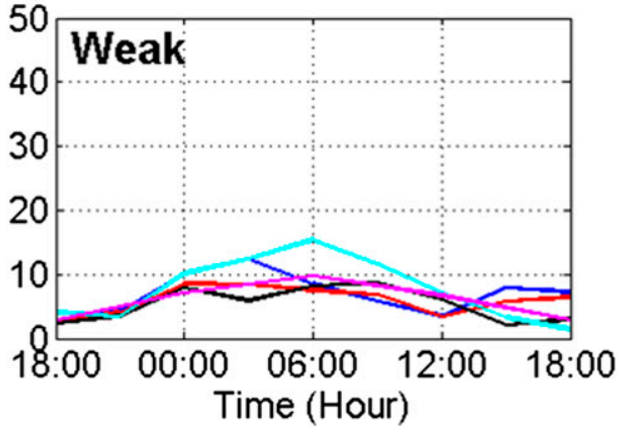

FIG. 2. (a) Surface wind speeds in the (left) WRF5, (center) WRF20, and (right) WRF60 for (top) the strong and (bottom) the weak wind events (Fig. 1) at the time when each of these products records the maximum wind speed. The white cross indicates the location where the maximum wind speed occurs in the respective simulation, and the white plus sign marks the location of the DMI station. (b),(c) Comparison of the wind speed evolution in WRF60, WRF20, and WRF5 at their locations of maximum wind speed, and the wind speed evolution in WRF1.7 at the location where WRF5 obtains the maximum wind speed. (d),(e) Comparison of the wind speed evolution in WRF5, WRF20, and WRF60 with the observed wind speed at the DMI station location. 

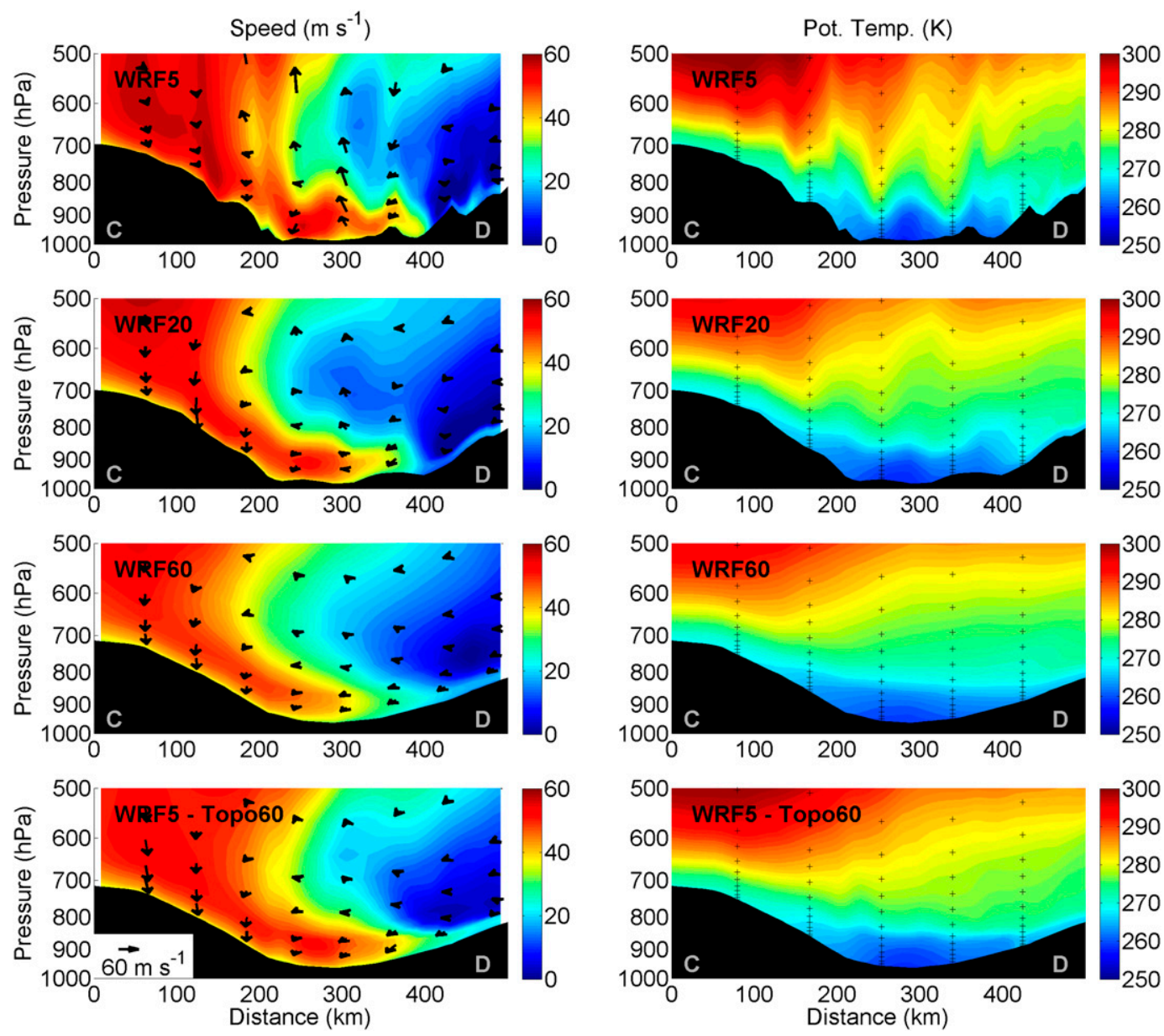

FIG. 3. Comparison of (left) flow field and (right) potential temperature in the WRF5, WRF20, and WRF60 across the section CD in Fig. 1. The filled contours show the component of the flow across the section, whereas the arrows represent the flow along this cross section. Only a few arrows are shown. The reference arrow is representative of the horizontal direction only. The vertical direction is rescaled according to the axis limits. WRF5-Topo60 indicates the case where the model resolution is $5 \mathrm{~km}$ and the topographic resolution is $60 \mathrm{~km}$. Black crosses overlaid on the temperature field indicate the positions of the vertical model levels at selected locations across the valley.

but the differences between WRF5, WRF20, and WRF60 remain.

Vertical sections along and across the flow confirm that the wind speed is larger with higher resolution (Figs. 3 and 4). WRF5 resolves two distinct regions of steep topography at the southwestern side of the valley, each associated with a wind speed maximum of up to $60 \mathrm{~m} \mathrm{~s}^{-1}$, that intermingle in the coarser-resolution domains (Fig. 3). The cross-sectional flow (represented by the arrows in Fig. 3) is entering the valley at both sides near the surface, which is likely a result of channeling by the topography. There is more vertical and horizontal wind shear in the wind field in WRF5 and a highly variable potential temperature field across the valley compared with the coarser resolutions. In WRF20, this variability is strongly reduced, and WRF60 almost does not see it at all. The differences between the domains are largest inside and along the edges of the valley, with differences of $10-20 \mathrm{~m} \mathrm{~s}^{-1}$. They do not only occur near the surface, where the different resolutions result in different representations of the topography, but they also extend up higher into the troposphere. If the model is run with a $60-\mathrm{km}$-resolution topography everywhere, the wind speed in WRF5 is still higher compared with WRF60, but is reduced compared with the WRF5 domain with the $5-\mathrm{km}$ topography, especially near the surface. The potential temperature field in WRF5 with the 60-km-resolution topography (WRF5-Topo60) is closer to the one in WRF60 than to the one in WRF5 with the 5-km topography. This shows that both smallscale topography and high-resolution dynamics play an important role during the wind events. 

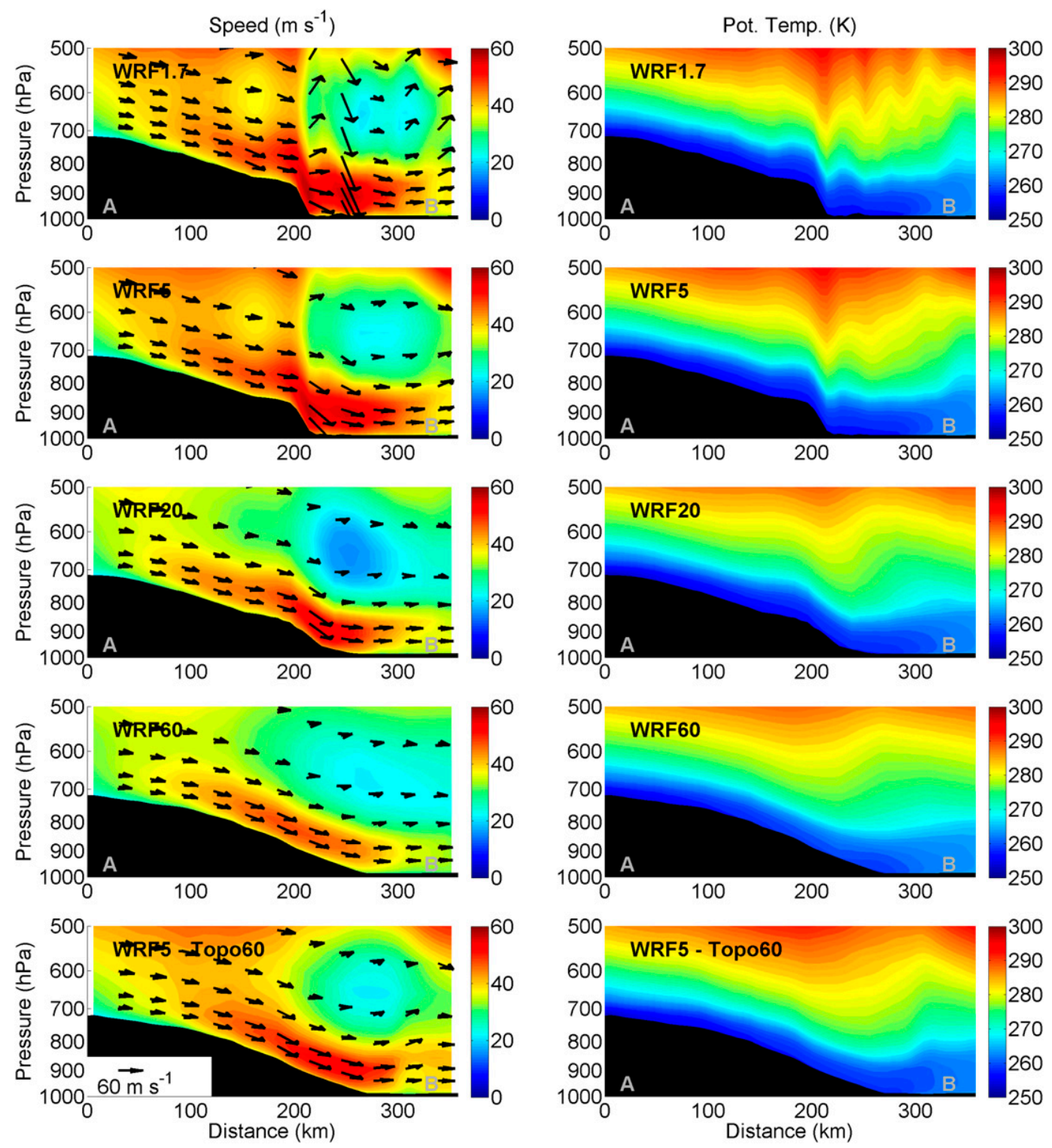

FIG. 4. Comparison of (left) flow field and (right) potential temperature in the WRF1.7, WRF5, WRF20, and WRF60 along the section AB in Fig. 1. Shown is the component of the flow along the section. The reference arrow is representative of the horizontal direction only. The vertical direction is rescaled according to the axis limits. WRF5Topo60 indicates the case where the model resolution is $5 \mathrm{~km}$ and the topographic resolution is $60 \mathrm{~km}$.

Using a higher resolution has a large effect on the slope along the valley, especially close to the coast (Fig. 4). The biggest differences in the wind speed between WRF5, WRF20, and WRF60 amount to about $20 \mathrm{~m} \mathrm{~s}^{-1}$ and occur near the surface where the slope is steepest. The potential temperature field in WRF5 suggests that the high wind speeds over the slope are associated with a steep mountain wave that is underrepresented in WRF20 and largely smoothed out in WRF60 (Fig. 4). In the WRF5Topo60 case, the wind speeds are still higher compared with WRF60, but, again, they are smaller compared with
WRF5 with the $5 \mathrm{~km}$ topography, and the wave in the potential temperature field is smoothed.

A comparison between WRF1.7 and WRF5 shows that the representation of the topography is similar in both domains, and over the slope the wind speed and potential temperature profile in WRF5 and WRF1.7 agree well. The obtained isentropic slopes are very similar, and the mountain wave over the slope has approximately the same wavelength of approximately $50 \mathrm{~km}$. The largest differences between WRF1.7 and WRF5 occur downstream of the coastline, where WRF1.7 resolves larger 
vertical velocities that are associated with a series of lee waves that are smoothed in WRF5. Such lee waves are a typical signature of downslope wind storms with a lower stable layer. They radiate energy away when the surface flow recovers toward ambient conditions (Durran 1990).

For the weak event, the overall wind speeds are smaller, but the profiles show the same graduation in wind speed and isentropic slopes between WRF5, WRF5-Topo60, WRF20, and WRF60. This suggests the existence of dynamical differences both between different resolution domains and between the smoothed and regular topography simulations. We will investigate these differences in the next section.

\section{b. Momentum balance}

To study the dynamical differences, we evaluate each term in the momentum balance for the downslope flow and investigate how it is affected by model resolution. To a good approximation, the atmospheric lapse rate is linear between 2500- and 6000-m heights. Below about $2000 \mathrm{~m}$, the temperature gradient is larger, and the near-surface air is significantly colder than above. Thus, we split the temperature into an ambient part $\theta_{0}$, which is obtained by linearly extrapolating the temperature between 2500 and $6000 \mathrm{~m}$ to the surface, and a temperature deficit part $\theta$, which is defined as the deviation from the linear temperature lapse rate such that a positive temperature deficit means the air in this layer is colder than the ambient air at the same height. Using higher bounds for the definition gives the same results. This procedure has also been applied by other studies on katabatic winds (Mahrt 1982; Parish and Cassano 2001, 2003; van Angelen et al. 2011), and we verified that the splitting is meaningful for each time step and model domain by confirming that the temperature lapse rate is approximately linear above $2500 \mathrm{~m}$. An example of this splitting can be seen in Figs. 8a and 9a for different time steps. We analyze the momentum balance along the same section $\mathrm{AB}$ that is shown in Figs. 1 and 5. This section goes right through the valley where the wind speed is maximum and the slope is steepest; thus, we expect this section to show the largest differences between the resolutions. In the downslope direction $x$ and in the model's vertical coordinate (Fig. 5), the momentum balance can be expressed as

$$
\begin{gathered}
\frac{\partial u}{\partial t}+\left.u \frac{\partial u}{\partial x}\right|_{z^{\prime} \cos (\alpha)}+v \frac{\partial u}{\partial y}+w \frac{\partial u}{\partial z^{\prime}}-f v \\
=\frac{g}{\theta_{0}} \theta \sin (\alpha)-\left.\cos (\alpha) \frac{g}{\theta_{0}} \frac{\partial \hat{\theta}}{\partial x}\right|_{z^{\prime}}-\left.\frac{1}{\rho_{0}} \frac{\partial p_{\mathrm{amb}}}{\partial x}\right|_{z}+F_{\mathrm{Res}} \\
F_{t}+F_{\mathrm{NL}}+F_{C}=F_{G}+F_{T}+F_{S}+F_{\mathrm{Res}}
\end{gathered}
$$

where $\rho_{0}$ is density; $f$ is the Coriolis parameter; $g$ is gravity; $\alpha$ is the positive angle of the slope with respect to the horizontal; $w$ is the velocity in the $z^{\prime}$ direction, normal to $u ; p_{\text {amb }}$ is the pressure in the ambient atmosphere corresponding to $\theta_{0}$; and $\hat{\theta}(z)$ is the vertically integrated temperature deficit from $z$ to some arbitrary height $z_{t}$, which is chosen above the boundary layer where the temperature deficit vanishes:

$$
\hat{\theta}(z)=\int_{z}^{z_{t}} \theta d z .
$$

In Eq. (2) the total horizontal pressure gradient force $F_{P}$ is split into an ambient pressure gradient acceleration $F_{S}$, the gravitational acceleration $F_{G}$, and the thermal acceleration $F_{T}$. The splitting between $F_{T}$ and $F_{G}$ arises from the rotation of the coordinate system in the downslope direction. The gravitational acceleration represents the acceleration due to the presence of a temperature deficit layer over sloping terrain. The ambient pressure gradient acceleration describes the acceleration due to pressure gradients in the ambient atmosphere, thus ignoring the deficit layer. Mountain wave effects are included mostly in this term. The thermal acceleration is due to temperature variations within the deficit layer. It is comparable to the coastal sea-breeze effect (Estoque 1961; Simpson 1994) and exists even in the absence of the slope.

We calculate $F_{S}, F_{T}$, the local acceleration $F_{t}$, nonlinear advection $F_{\mathrm{NL}}$, and $F_{G}$ explicitly at $2100 \mathrm{UTC}$ and infer subgrid-scale dynamics $F_{\text {Res }}$ from the residual. The ambient pressure gradient acceleration within the boundary layer can be calculated using hydrostatic balance and integrating the ambient potential temperature gradient downward (Cassano and Parish 2000; Van den Broeke et al. 2002; van Angelen et al. 2011). We verified that the flow is in hydrostatic balance by evaluating the vertical momentum equation for the ambient and the full atmosphere in each domain along the section AB. Even in WRF1.7, the hydrostatic terms are approximately one order of magnitude larger than their difference and several orders of magnitude larger than the advective terms and local acceleration. Thus,

$$
\begin{aligned}
\left.\frac{1}{\rho} \frac{\partial p_{\mathrm{amb}}}{\partial x}\right|_{z}= & \left.\frac{1}{\rho} \frac{\partial p\left(z_{t}\right)}{\partial x}\right|_{z} \\
& +\left.R_{g} \int_{\ln p(z)}^{\ln p\left(z_{t}\right)}\left(\frac{p}{p_{0}}\right)^{R_{g} / c_{p}} \frac{\partial \theta_{0}}{\partial x}\right|_{p} d \ln p \quad \text { and } \\
\left.\frac{1}{\rho} \frac{\partial p_{\mathrm{amb}}}{\partial y}\right|_{z}= & \left.\frac{1}{\rho} \frac{\partial p\left(z_{t}\right)}{\partial y}\right|_{z} \\
& +\left.R_{g} \int_{\ln p(z)}^{\ln p\left(z_{t}\right)}\left(\frac{p}{p_{0}}\right)^{R_{g} / c_{p}} \frac{\partial \theta_{0}}{\partial y}\right|_{p} d \ln p
\end{aligned}
$$




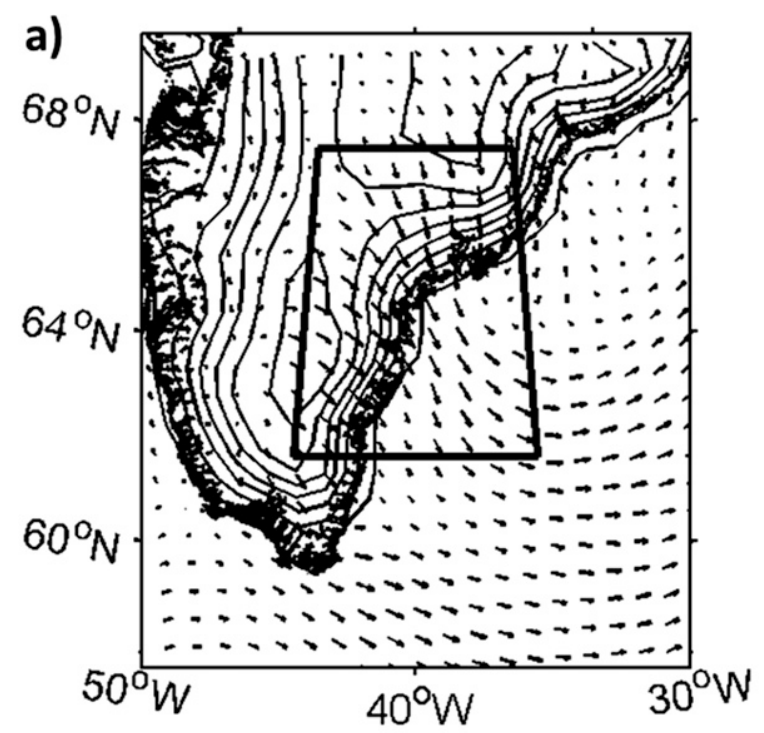

b)

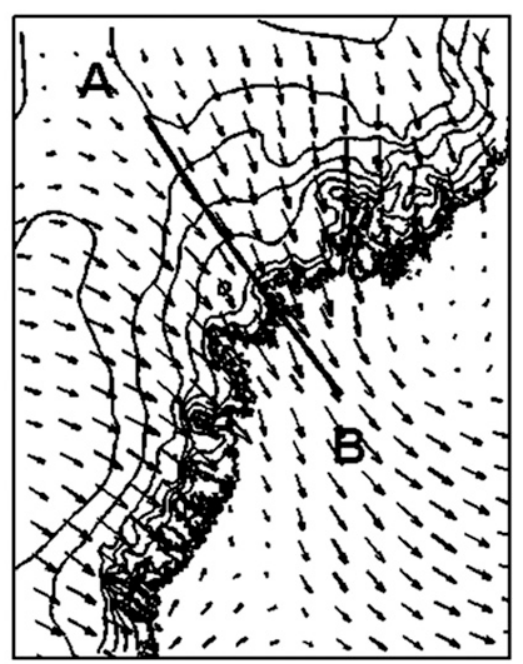

c)

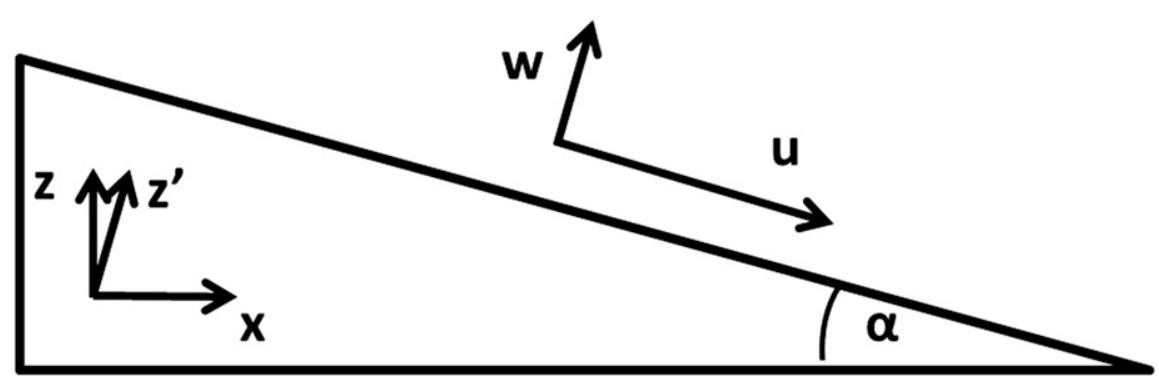

FIG. 5. Topography in the (a) WRF60 and the (b) WRF5 domains with surface velocity vectors overlaid. Only a few arrows are shown. The contour interval is $400 \mathrm{~m}$. (c) Schematic of the coordinate system used for the analysis of the momentum balance (Fig. 6).

where $R_{g}$ is the gas constant and $c_{p}$ is the heat capacity at constant pressure. Under nonhydrostatic conditions, the total horizontal pressure gradient within the temperature deficit layer would consist of an additional term because of nonhydrostatic pressure effects $F_{\mathrm{NH}}=F_{P}-F_{T}-F_{G}-F_{S}$, which can also include inaccuracies resulting from the differentiation in $F_{P}$. We find that this term has a horizontally uniform distribution over the slope, and its magnitude remains below $10^{-3} \mathrm{~m} \mathrm{~s}^{-2}$. Moreover, it is insensitive to resolution, which agrees with previous studies on katabatic winds in Antarctica (Cassano and Parish 2000). To compare the forces in WRF5 and WRF60 on the same scales and to remove the high-frequency variability associated with the mountain wave in WRF5, we smooth them over a distance of $120 \mathrm{~km}$. Other filter sizes give the same result as long as they smooth out local variability associated with the wave in WRF5. The forces are shown in Fig. 6, apart from the local acceleration, which is negligible.

We find that all forces have a larger magnitude in WRF5 compared to WRF60. The biggest differences occur in the dominant terms $F_{G}, F_{S}$, and $F_{\mathrm{NL}}$. The term $F_{S}$ is initially accelerating the wind, but as the flow approaches the coast, it inhibits the surface flow. Both the acceleration and the deceleration are more pronounced in WRF5 than in WRF60, with differences above $20 \%$. The difference in the magnitude of $F_{G}$ is similarly large. In both domains, it is the largest accelerating force over the central part of the slope. Advection $F_{\mathrm{NL}}$ is mostly responding to the other forces. It can be split into a horizontal alongslope, a horizontal cross-slope, and a vertical component. The horizontal components are large and positive at the surface of the slope and negative above (not shown), whereas the vertical component is negative at the surface and positive above (Fig. 7). This is in line with previous studies, which suggest that the horizontal momentum flux of the intense surface flow is balanced by vertical advection of momentum (Durran 1986; Bacmeister and Pierrehumbert 1988). In these studies, however, the horizontal momentum advection includes mostly the along-slope component. For both wind events here, we note that the cross-slope horizontal component is similarly large (not shown), likely because of confluence of the flow inside the valley. This stresses the importance of $3 \mathrm{D}$ effects for the wind events. 

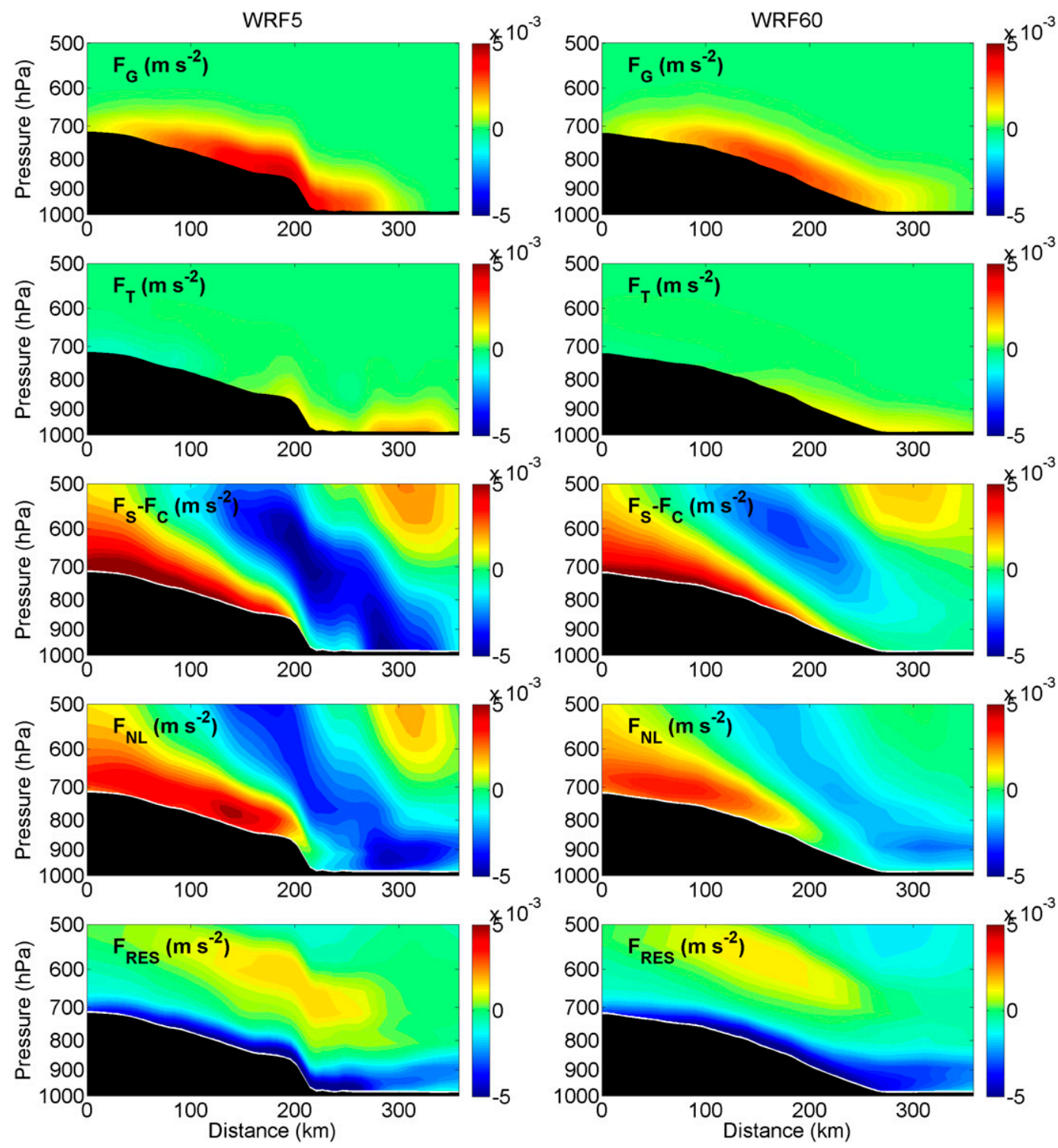

FIG. 6. Accelerations during the strong event in (left) WRF5 and (right) WRF60 along the section AB shown in Fig. 1. Shown are (top to bottom) the gravitational acceleration $F_{G}$, thermal acceleration $F_{T}$, ambient pressure gradient and Coriolis acceleration $F_{S}-F_{C}$, nonlinear advection $F_{\mathrm{NL}}$, and the residual $F_{\mathrm{Res}}$ at $2100 \mathrm{UTC}$. $F_{\mathrm{NL}}$ appears on the left-hand side of Eq. (2) and is mostly balancing the pressure gradient terms. The forces are smoothed over $120 \mathrm{~km}$ to eliminate the small-scale variability associated with the mountain wave and to compare WRF5 and WRF60 on the same scale.

In WRF5 and WRF60, $F_{\text {Res }}$ has a similar magnitude. It includes effects of subgrid-scale turbulence that are parameterized in the model, numerical inaccuracies resulting from the differentiation, and the local tendency of the momentum, which is not fully included in the local acceleration because of the coarse temporal sampling of $3 \mathrm{~h}$. Since $F_{\text {Res }}$ has a similar magnitude in WRF5 and WRF60, there is little or no parameterization of the nonlinear effects on scales between 5 and $60 \mathrm{~km}$. Thus, there is no gravity wave drag parameterization, which is currently not supported for simulations of this duration and resolution in the WRF Model. Close to the surface, where friction is important, $F_{\text {Res }}$ is strongly decelerating the flow. Above the surface, it is negligible, except over the steepest part of the slope above the surface layer, where it is accelerating the flow. Since this region corresponds to a local minimum in wind speed (Fig. 4) the acceleration could result from drag by the faster flow around it. The local acceleration (not shown) and the thermal acceleration are relatively unimportant compared with the 


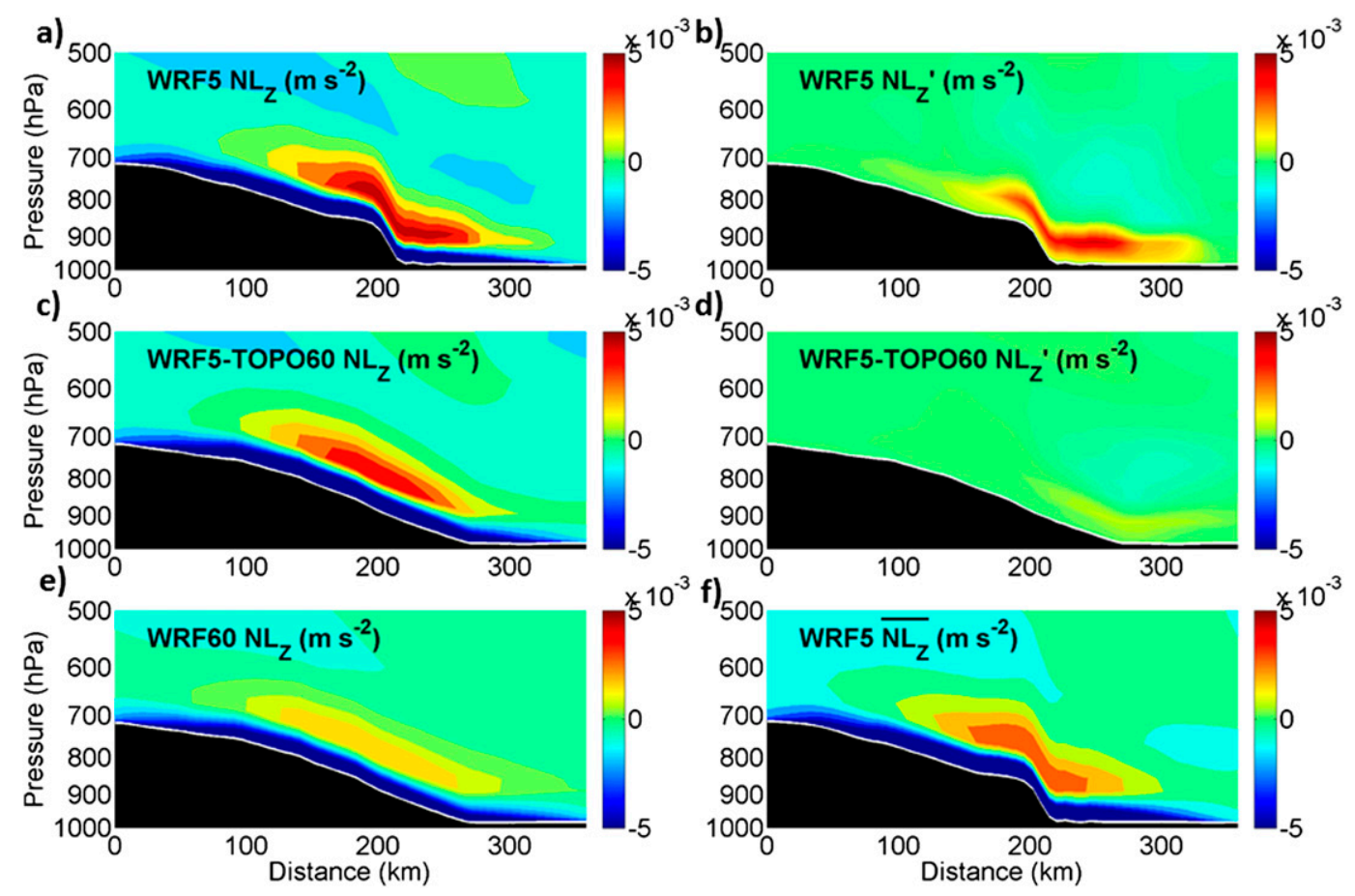

FIG. 7. Mean and wave parts of the vertical component of the momentum flux along section AB (Fig. 1) at 2100 UTC. (left) Total vertical momentum flux in (a) WRF5, (c) WRF5-Topo60, and (e) WRF60. (right) Wave component of the vertical momentum flux $\left(\overline{w^{\prime} \partial u^{\prime} / \partial z}\right)$ in (b) WRF5 and (d) WRF5-Topo60, and (f) mean component of the vertical momentum flux in WRF5 $(\bar{w} \partial \bar{u} / \partial z)$.

other forces, both in WRF5 and WRF60. For the WRF5Topo60 case (not shown), the magnitude of the forces is larger compared with WRF60 (especially for $F_{G}, F_{S}$, and $\left.F_{\mathrm{NL}}\right)$ and smaller compared with WRF5.

Previous studies have explained strong surface wind speeds by large vertical momentum fluxes associated with mountain waves (Durran 1986; Bacmeister and Pierrehumbert 1988; Durran 2003). To directly assess the importance of momentum fluxes on the scales not resolved in WRF60, we decompose the (unrotated) flow into a mean component and a wave component $\left(u=\bar{u}+u^{\prime}\right.$ and $\left.w=\bar{w}+w^{\prime}\right)$. We define the mean as a running mean over $120 \mathrm{~km}$ on the model levels and the wave component as deviations of the flow from the mean. Thus, by definition, the wave component in WRF60 is negligible. In WRF5, WRF60, and WRF5Topo60, momentum converges over the slope above the surface (Fig. 7). In WRF5, the wave component of the vertical momentum flux $\left(N L_{Z}^{\prime}=\overline{w^{\prime} \partial u^{\prime} / \partial z}\right)$ can be almost twice as large as the mean component $\left(\overline{N L_{Z}}=\bar{w} \partial \bar{u} / \partial z\right)$. The mean component of the vertical momentum flux in WRF5 also has a larger magnitude than the total vertical momentum flux in WRF60; thus, these wave processes have a large impact on the mean flow. In the WRF5Topo60 case, the magnitude of the total vertical momentum flux is reduced compared to WRF5 but larger compared to WRF60. The wave component is very small despite the 5-km model resolution, emphasizing the role of the topography in setting the scale of the dynamics (Fig. 7).

\section{c. Mountain wave-gravity current interaction}

The results from the previous section indicate that the driving forces of the downslope flow have a different magnitude in WRF5 and WRF60, even on scales greater than $120 \mathrm{~km}$ (Fig. 6). Apart from the differences in the nonlinear advection, the largest differences between the domains occur in the ambient pressure gradient and the gravitational acceleration. Given the importance of the steep slope for the cross-mountain pressure drag, the different representation of $F_{S}$ in WRF5 and WRF60 is expected. On the other hand, $F_{G}$ depends only on the height difference of the two end points of the part of the slope over which it is averaged, as well as the temperature deficit. Both quantities are not directly affected by the resolution when averaged over the slope. Thus, the only way by which $F_{G}$ can attain a different magnitude in WRF5 and WRF60 is by nonlinear effects when the temperature deficit is increased at exactly those locations where the slope is steeper in the higher-resolution domain and by feedbacks with the other forces (e.g., when a stronger flow results in more cold-air advection, which in turn intensifies the temperature deficit and $F_{G}$ ). 
a)
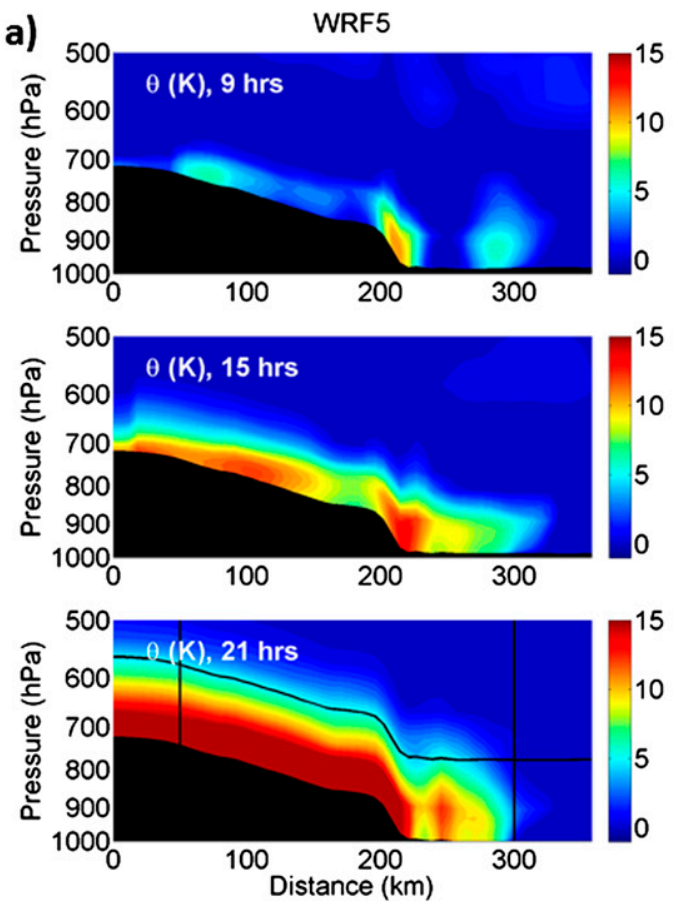

WRF60
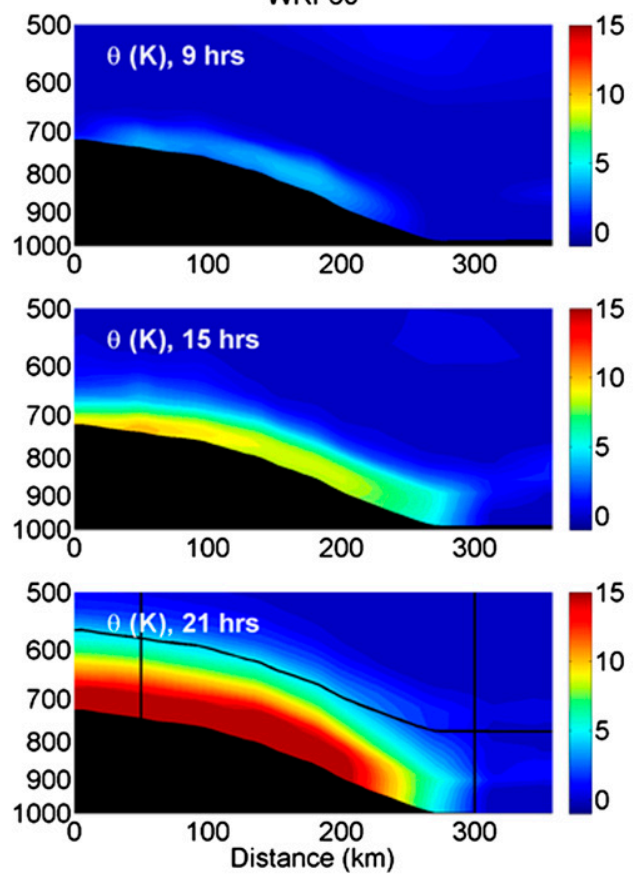

b)

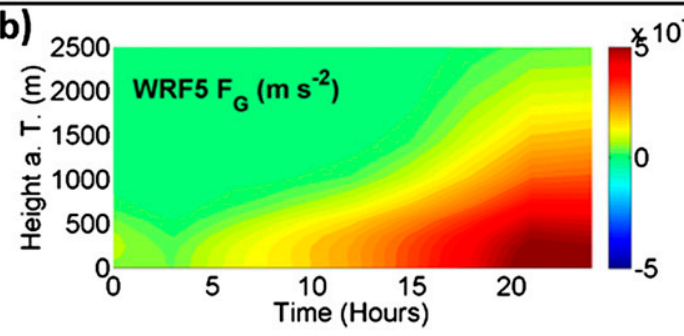

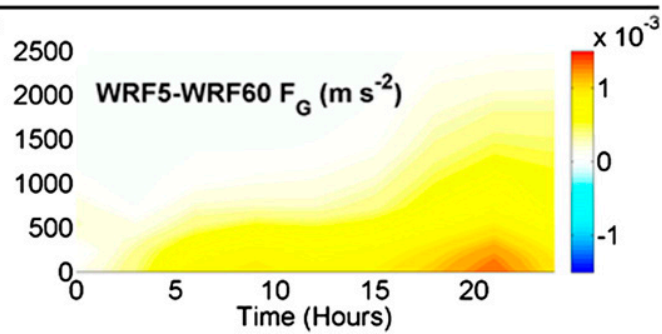

FIG. 8. (a) Evolution of the temperature deficit along section AB (Fig. 1) at three different time steps during the simulation of the strong wind event for WRF5 and WRF60. In WRF5, the temperature deficit intensifies faster, especially over the steeper parts of the slope, which results in a larger gravitational acceleration. The lines at $21 \mathrm{~h}$ delineate the location of the 10 lowest model levels and region between 50 and $300 \mathrm{~km}$ that is used for the averaging in Fig. 10. (b) Evolution of the gravitational acceleration averaged between 50 and $300 \mathrm{~km}$ in WRF5 and the difference between WRF5 and WRF60. The difference increases with time.

Interactions between gravitationally driven flows and mountain waves have been studied by Poulos et al. (2000, 2007) for different Froude number regimes. Using an upstream wind speed of $30 \mathrm{~m} \mathrm{~s}^{-1}$ for the strong wind event, a stability of $N=0.02 \mathrm{~s}^{-1}$, and a mountain height of $3000 \mathrm{~m}$, the Froude number is close to 0.5 for the strong wind event. For the weak wind event, the upstream wind speed is about $20 \mathrm{~m} \mathrm{~s}^{-1}$, and $N$ is comparable to the strong wind event, resulting in a Froude number of approximately 0.33 . The higher Froude number for the strong wind event is associated with a mountain wave separation point that is shifted downhill. The mountain wave separation point delimits the region where the mountain wave dominates the flow. According to Poulos et al. (2000, 2007), the coupling of the katabatic wind with the mountain wave downstream of the separation point can deepen the temperature deficit layer by turbulence relative to the case without mountain waves. Indeed, for both wind events, we find very deep deficit layers of more than $1000 \mathrm{~m}$ (e.g., Figure 8). Another effect of mountain waves on katabatic flows arises from pressure perturbations that are induced by the gravity waves above the temperaturedeficit layer (Poulos et al. 2000, 2007). We find this is true for both wind events, as the temperature deficit is not distributed evenly over the slope. In WRF5, the temperature deficit increases more quickly over the steeper parts of the slope, which results in a larger gravitational acceleration in WRF5 compared to WRF60, and the difference increases with time as more cold air is advected onto the slope (Fig. 8). Thus, the mountain wave-katabatic wind interaction leads to a stronger gravitational acceleration in WRF5 compared with WRF60. 
a)
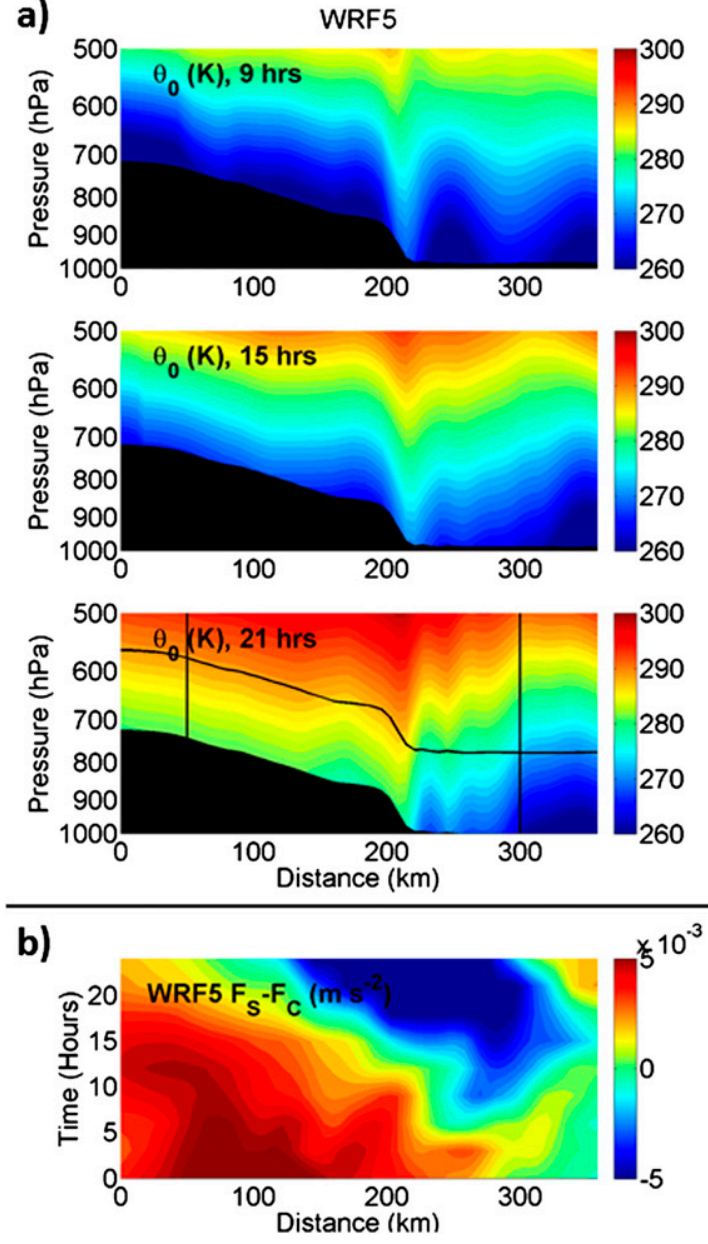
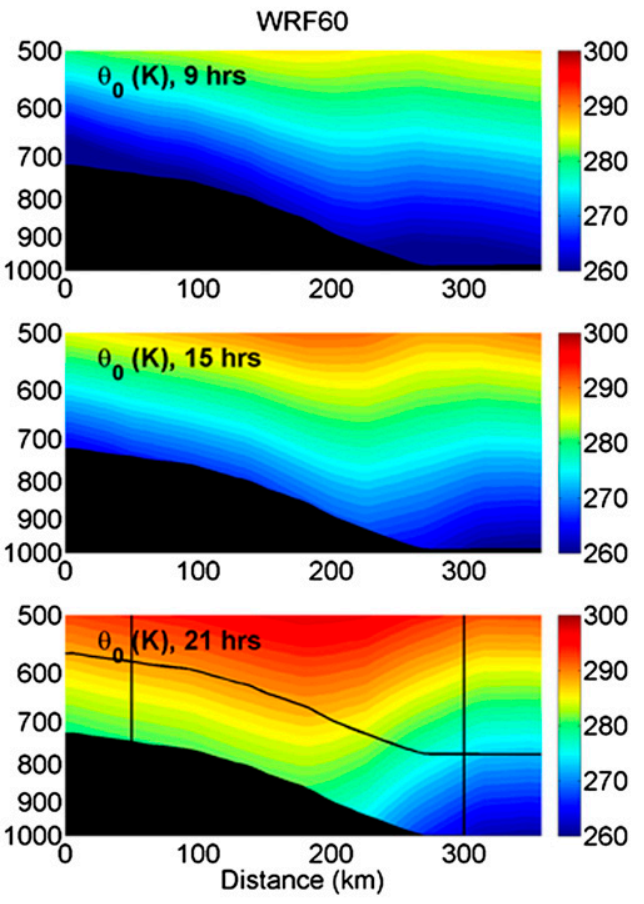

FIG. 9. (a) Evolution of the ambient temperature along section AB (Fig. 1) at three different time steps during the simulation of the strong wind event for WRF5 and WRF60. The advection of strongly stratified air over the ocean results in a decelerating horizontal pressure gradient in WRF5 and WRF60, which is more pronounced in WRF5. The lines at $21 \mathrm{~h}$ delineate the location of the 10 lowest model levels and region between 50 and $300 \mathrm{~km}$ that is used for the averaging in Fig. 10. (b) Evolution of the ambient pressure gradient acceleration averaged over the 10 lowest model levels in WRF and the difference between WRF5 and WRF60. Note that the axes are different from the ones in Fig. 8b. The decelerating effect of the pressure gradient force is seen farther upslope with time and intensifies.

Poulos et al. (2007) suggested that mountain waves and katabatic winds can sometimes become indistinguishable and inseparable. Despite the close interaction between them, we still note that the splitting of the total pressure gradient force into $F_{G}$ and $F_{S}$ is meaningful at each time step. As the simulation of the strong wind event progresses, a cold-air pool forms at the end of the slope and extends deep into the atmosphere. Thereby, $F_{S}$ decreases and is decelerating the flow at the end of the slope. The region where $F_{S}$ is negative shifts farther upslope as more cold air is advected downslope. Thus, there is a negative feedback between the stronger flow and the decreasing ambient pressure gradient force (Fig. 9), and this feedback is more pronounced in WRF5. In summary, for the strong wind event, the temperature profile first develops large vertical gradients when the deficit layer intensifies and then develops large horizontal gradients. The former process accelerates the flow as described by $F_{G}$, and the latter decelerates the flow as described by $F_{S}$.

For the weak event, the gravitational acceleration is initially larger than the ambient pressure gradient acceleration. Since the Froude number is smaller, the katabatic component of the flow is more pronounced (Poulos et al. 2000). While the downslope wind speed increases, a wave develops over the slope, but it is shallower compared with the strong wind event, and the separation point is shifted upslope. The development of the wave is associated with an increase of the ambient pressure gradient acceleration. Meanwhile, the temperature deficit 

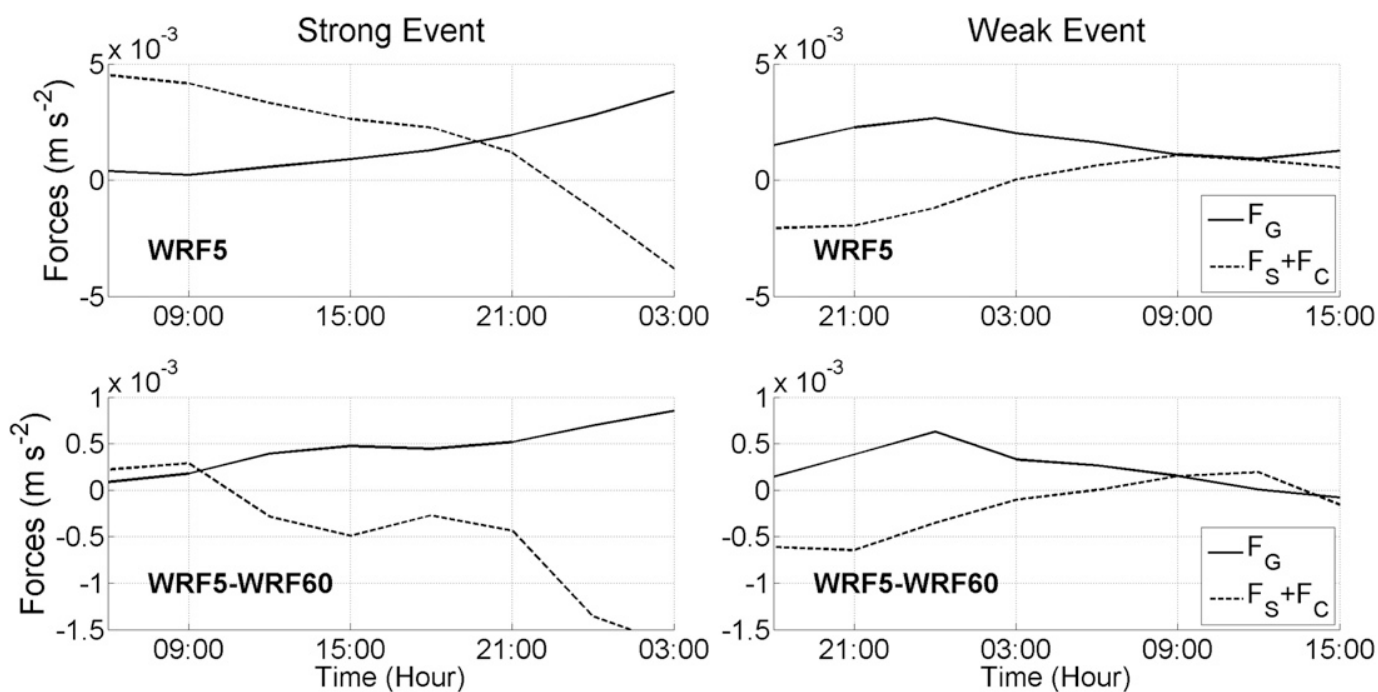

FIG. 10. Evolution of the ambient pressure gradient and Coriolis acceleration (dashed) and the gravitational acceleration (solid) averaged over the 10 lowest model levels and the region between 20 and $300 \mathrm{~km}$ over the slope along section $\mathrm{AB}$ in Fig. 1. The region over which it is averaged is shown in Figs. 8 and 9. Shown are the evolutions for (left) the strong and (right) the weak wind events in (top) WRF5 and (bottom) WRF60, as well as their differences (WRF5 minus WRF60).

layer mixes with ambient air and the stratification and, thus, $F_{G}$ decreases (not shown). To summarize the evolution of the differences in WRF5 and WRF60 for the strong and the weak wind events, we average the forces over the 10 lowest model levels between the distances of 50 and $300 \mathrm{~km}$ over the slope (see Figs. 8 and 9). The results are insensitive to the vertical extent of the lower layer and the distance over which we average. For the strong wind event, the magnitude of the forces is larger compared with the weak wind event, and the evolution diverges between WRF5 and WRF60. For the weak event, the differences between WRF and WRF60 remain small (Fig. 10).

\section{d. Effects on larger scales}

Next, we investigate how far downstream the effects of using a higher resolution extend and compare the evolution of the surface pressure, temperature, wind speed, and total turbulent heat fluxes in the simulations with the one- and the two-way nesting. Thus, we compare these fields in WRF60 from the simulation when feedbacks from WRF5 and WRF20 are included with the one from the simulation that does not allow for feedbacks (Fig. 11). We do not expect the simulations to diverge because of intrinsic model variability, since they are still strongly controlled by the initial conditions within the simulation period of $24 \mathrm{~h}$. Again, for the strong wind event, the differences are more pronounced compared with the weak one (not shown), and they quickly increase with time. If feedbacks are included, the pressure is lower in the outflow region of the Ammassalik valley and higher northeast of it over the Irminger Sea. Near the east Greenland coast, this results in a narrowing of the shape of the low pressure system. In addition, the surface air in the outflow region of the valley (Fig. 2 ) is colder by about $2 \mathrm{~K}$, and the winds are faster by about $5 \mathrm{~m} \mathrm{~s}^{-1}$ downstream of Ammassalik. This has consequences for the turbulent heat fluxes, which amount to $1000 \mathrm{~W} \mathrm{~m}^{-2}$ and are up to $200 \mathrm{~W} \mathrm{~m}^{-2}$ larger in the region of the highest wind speeds and up to $200 \mathrm{~W} \mathrm{~m}^{-2}$ weaker south of this region. Positive heat fluxes indicate that heat is transferred from the ocean to the atmosphere. Thus, differences between the one- and the two-way nesting simulations are not confined to the valley in Ammassalik but extend downstream over the Irminger Sea, where they result in a different spatial distribution and temporal evolution of the heat fluxes.

\section{Discussion and conclusions}

In this study, we have investigated the role of small-scale dynamics and steep topography for strong downslope wind events (DWE) in southeast Greenland and their downstream effects. Specifically, we have simulated a strong and a weak wind event with the WRF Model in a 60- (WRF60), a 20- (WRF20), and a 5-km (WRF5)resolution domain with a smoothed and a regular topography. We have found that these different resolutions result in different representations of the wind field and its underlying dynamics. The differences are present for both 

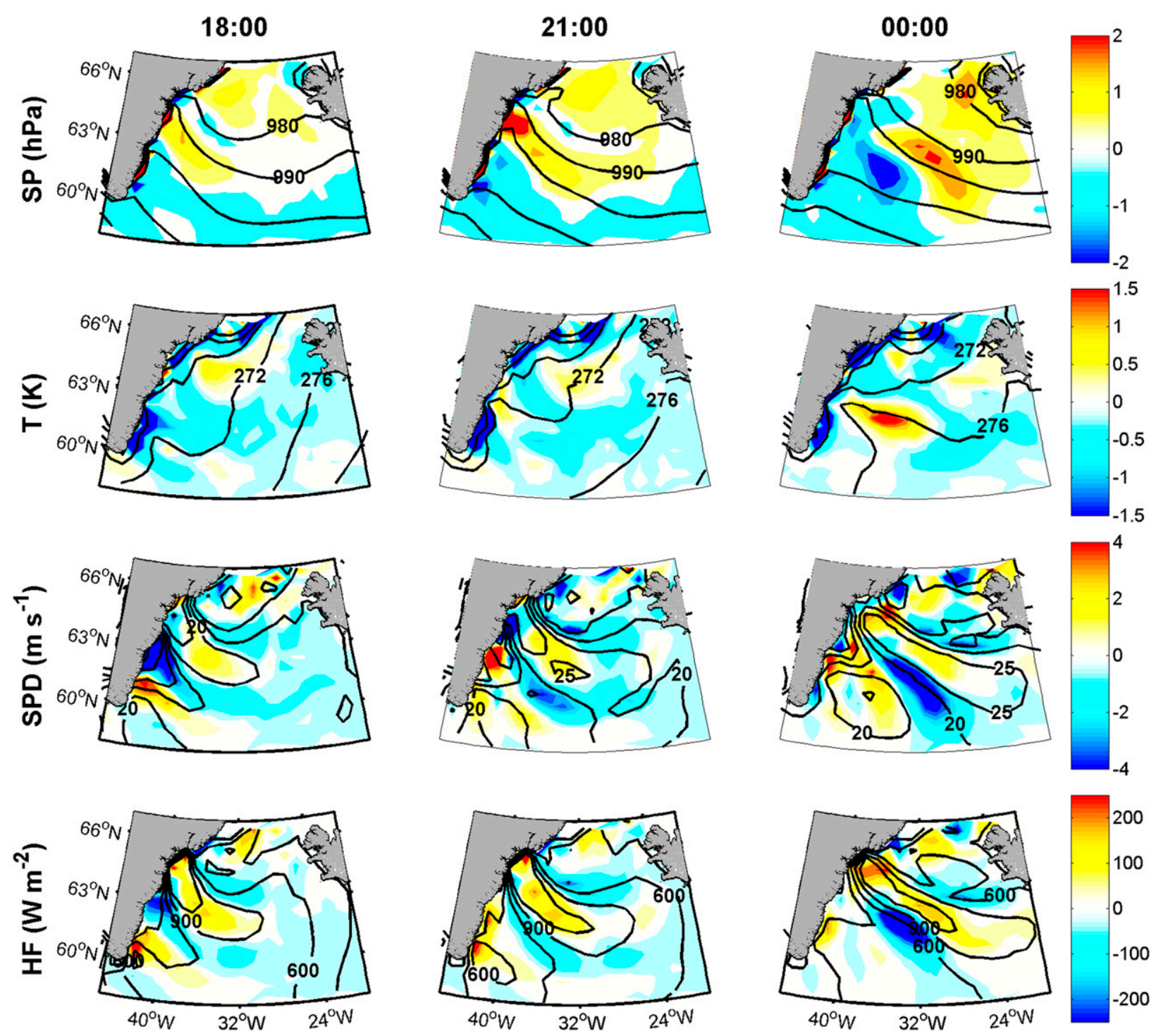

FIG. 11. Black contour lines: evolution of the (top to bottom) surface pressure, temperature, wind speed, and heat fluxes for the strong event in WRF60 from the simulation with the two-way nesting. Contour lines are every $10 \mathrm{hPa}, 4 \mathrm{~K}, 5 \mathrm{~m} \mathrm{~s}^{-1}$, and $300 \mathrm{~W} \mathrm{~m}^{-2}$, respectively. Filled contours: differences between the simulations with the one- and two-way nesting. Positive values indicate that the displayed quantity is higher in the simulation that allows for feedbacks from the inner domains compared with the one without feedbacks. Positive heat fluxes represent a heat flux from the ocean to the atmosphere.

events, but they are larger for the strong one. Since the boundary and initial conditions for the two events from ERA-I are representative of the composite, the sensitivity to model resolution is likely a common feature of DWE. If the model is run on a $5-\mathrm{km}$-resolution grid but with a $60-\mathrm{km}$-resolution topography, there are still significant differences, even though their overall magnitude is reduced. Thus, both a high-resolution model and a high-resolution topography are needed to simulate the full extent of DWE.

The largest differences between the WRF5, WRF20, and WRF60 domains occur at the southwestern side of the valley near the surface and over the slope inside the valley (Fig. 3). The first could be attributed to a stronger pressure gradient buildup when the flow is dammed against the barrier, similar to barrier winds at the coast (Moore and Renfrew 2005; Petersen et al. 2009; Harden et al. 2011), but here the barrier is represented by the southwestern side of the valley, and rotation is likely less important as a result of the smaller scale. There is a sharp turning of the isobars inside the valley (Fig. 1). Over the upper part of the slope, the pressure gradient is accelerating the flow, whereas it is decelerating the flow over the lower part (Fig. 6). Thus, the coarser representation of 
the topography and smaller pressure gradients in the lower-resolution domains are associated with a weaker flow near the southwestern side of the valley and a reduced horizontal and vertical wind shear. When the model is run on a $5-\mathrm{km}$-resolution grid but with a $60-\mathrm{km}$ resolution topography, the flow field is similar to the one in the WRF60 domain, which emphasizes the role of the topography.

In addition, there is a steep mountain wave in WRF5 with the regular topography near the end of the slope, where the wind speeds are particularly strong (Fig. 4). Previous studies suggest that mountain waves are associated with a large vertical momentum flux that accelerates the surface winds (Durran 1986; Bacmeister and Pierrehumbert 1988; Durran 2003). WRF60 does not resolve the full extent of the vertical momentum transfer. If the 60-km-resolution topography is used, the vertical momentum flux in WRF5 is reduced but still larger compared with WRF60 (Fig. 7). The differences between WRF5 with the smoothed and regular topography are solely due to the resolution of the topography. They likely arise because the vertical momentum flux due to the cross-mountain pressure drag is sensitive to the terrain slope (Doyle et al. 2005). The fact that the magnitude of the vertical momentum flux in WRF5 with the $60-\mathrm{km}$-resolution topography is still larger than in WRF60 emphasizes the role of small-scale model dynamics. We conclude that surface wind speeds over the slope are sensitive to both model and topography resolution but also that these two are connected. A high model resolution is needed in order to simulate the wave dynamics, but the strength of the wave dynamics depends on the terrain slope.

Since the cross-mountain pressure drag is sensitive to the terrain slope, differences in the obtained magnitude of the ambient pressure gradient $F_{S}$ are expected. The fact that the gravitational acceleration $F_{G}$ also attains a different magnitude in WRF5 and WRF60 could be explained by interactions between $F_{G}$ and $F_{S}$, especially during the strong wind event. Specifically, horizontal pressure gradient perturbations induced by the mountain wave intensify the temperature deficit at exactly those locations where the slope is steepest, thus resulting in a larger gravitational acceleration in WRF5 compared with WRF60 (Fig. 8). Simultaneously, the downslope advection of stratified air leads to a cold-air pool at the end of the slope, likely because the air accumulates at the narrow valley outlet (Fig. 9). This is associated with a decrease of $F_{S}$ that is larger in WRF5 and could result in a different wind speed evolution in WRF5, WRF20, and WRF60 (Figs. 2 and 11). Currently, the WRF Model does not support a gravity wave parameterization for simulations of this duration and resolution, though our results suggest that future releases might benefit from it. Since the wave drag can interact with the gravitational acceleration, any parameterization would have to take this interaction into account.

The different evolution of the wind event in WRF5 and WRF60 is more pronounced for the strong wind event than for the weak one. As Poulos et al. (2000) suggest, this could be explained by the smaller Froude number for the weak wind event, which indicates that the katabatic component of the flow is more pronounced. Since the gravitational acceleration is less sensitive to resolution when averaged over the slope, the evolution of the weak wind event is more similar in WRF5 and WRF60.

Even a 5-km resolution could potentially misrepresent nonhydrostatic gravity waves and alias energy into longerwavelength hydrostatic waves (Reinecke and Durran 2009). Thus, we compared the flow and potential temperature field from WRF5 to an additional domain with a horizontal grid spacing of $1.67 \mathrm{~km}$ and 45 vertical levels (WRF1.7). We find that the surface and near-surface winds in WRF5 and WRF1.7 are in good agreement (Figs. 2 and 4) and that WRF5 captures the steepness of the topography. The largest differences between the two domains occur downstream of the coast, where WRF1.7 resolves a series of lee waves that are smoothed in WRF5. Since these lee waves do not affect the near-surface wind field over the slope, we conclude that the $5-\mathrm{km}$ resolution is adequate for the analysis in this study. Moreover, the wind speed in WRF5 is in good agreement with observations from a local weather station (Fig. 2), indicating that the effect of nonhydrostatic waves is limited near the surface and that the valley is wide enough to force primarily longer-wavelength hydrostatic waves. For steeper topography, faster flows and higher Froude numbers, nonhydrostatic effects can become more important (Ulrich 1991), and a separation of the pressure gradient force might not be meaningful anymore. To simulate wind events under such conditions, an even higher resolution is recommended.

The effects of resolving small-scale processes over the slope extend downstream over the Irminger Sea (Fig. 11). Thus, the faster downslope winds in WRF5 for the strong wind event do not only influence the local population and environment in Ammassalik, but have further-reaching climatic consequences. If feedbacks from WRF5 and WRF20 are included in WRF60, even large-scale fields, such as surface pressure and temperature, are affected. It is possible that the faster decrease of the ambient pressure gradient also affects the largerscale pressure distribution. This could result in a diverging evolution of the synoptic situation. Additional studies are required to investigate how sensitive the 
large-scale evolution is to small-scale processes over steep topography.

Moreover, depending on whether the nesting in Ammassalik is one- or two-way, the downstream wind field and heat fluxes over the Irminger Sea have both a different distribution and a different magnitude, with differences of up to about $200 \mathrm{~W} \mathrm{~m}^{-2}$. Since the turbulent heat fluxes depend on both wind speed and the airsea temperature difference, the discrepancy between the simulations is likely a consequence of the faster and colder air in the WRF5 domain. This suggests that the differences arising from the narrower and more intense outflow out of the valley extend beyond the WRF5 domain boundaries, and that the temperature and wind speed differences concur in their effect on the latent and sensible heat fluxes. Convection in the ocean depends on the air-sea heat exchange (Marshall and Schott 1999), and changes in the spatial distribution of the heat fluxes could result in shifts of the atmospheric forcing region relative to the ocean convection centers. Thus, including or neglecting small-scale processes in the Ammassalik valley in the model could have implications for the model's ability to correctly force deep-water formation.

Acknowledgments. This study was supported by grants of the National Science Foundation (OCE0751554 and OCE-1130008) as well as the Natural Sciences and Engineering Research Council of Canada. We thank ECMWF for providing the reanalysis data and UCAR for providing the WRF Model. We also gratefully appreciate the help of the WRF help team and the constructive comments of three anonymous reviewers!

\section{REFERENCES}

Amundson, J. M., M. Fahnestock, M. Truffer, J. Brown, M. Lüthi, and R. Motyka, 2010: Ice mélange dynamics and implications for terminus stability, Jakobshavn Isbræ, Greenland. J.Geophy. Res., 115, F01005, doi:10.1029/2009JF001405.

Bacmeister, J., and R. Pierrehumbert, 1988: On high-drag states of nonlinear stratified flow over an obstacle. J. Atmos. Sci., 45, 63-80, doi:10.1175/1520-0469(1988)045<0063:OHDSON > 2.0.CO;2.

Born, E. W., and J. B. Böcher, 2000: Wind conditions. The Ecology of Greenland, Atuakkiorfik Education, 72-74

Cassano, J. J., and T. R. Parish, 2000: An analysis of the nonhydrostatic dynamics in numerically simulated Antarctic katabatic flows. J. Atmos. Sci., 57, 891-898, doi:10.1175/ 1520-0469(2000)057<0891:AAOTND>2.0.CO;2.

Chen, F., and J. Dudhia, 2001: Coupling an advanced land surfacehydrology model with the Penn State-NCAR MM5 modeling system. Part I: Model implementation and sensitivity. Mon. Wea. Rev., 129, 569-585, doi:10.1175/1520-0493(2001)129<0569: CAALSH $>2.0 . \mathrm{CO} ; 2$.

Clark, T. L., W. D. Hall, R. M. Kerr, D. Middleton, L. Radke, F. M. Ralph, P. J. Neiman, and D. Levinson, 2000: Origins of aircraft-damaging clear-air turbulence during the 9 December
1992 Colorado downslope windstorm: Numerical simulations and comparison with observations. J. Atmos. Sci., 57, 1105-1131, doi:10.1175/1520-0469(2000)057<1105:OOADCA > 2.0.CO;2.

Dee, D. P., and Coauthors, 2011: The ERA-Interim reanalysis: Configuration and performance of the data assimilation system. Quart. J. Roy. Meteor. Soc., 59, 141-161, doi:10.1002/qj.828.

Dörnbrack, A., and T. Dürbeck, 1998: Turbulent dispersion of aircraft exhausts in regions of breaking gravity waves. Atmos. Environ., 32, 3105-3112, doi:10.1016/S1352-2310(97)00503-7.

Doyle, J. D., M. A. Shapiro, Q. Jiang, and D. L. Bartels, 2005: Large-amplitude mountain wave breaking over Greenland. J. Atmos. Sci., 62, 3106-3126, doi:10.1175/JAS3528.1.

Dudhia, J., 1989: Numerical study of convection observed during the winter monsoon experiment using a mesoscale twodimensional model. J. Atmos. Sci., 46, 3077-3107, doi:10.1175/ 1520-0469(1989)046<3077:NSOCOD>2.0.CO;2.

Durran, D. R., 1986: Another look at downslope windstorms. Part I: The development of analogs to supercritical flow in an infinitely deep continuously stratified fluid. J. Atmos. Sci., 43, 2527-2543, doi:10.1175/1520-0469(1986)043<2527:ALADWP>2.0.CO;2.

- 1990: Mountain waves and downslope winds. Atmospheric Processes over Complex Terrain, Meteor. Monogr., No. 45, Amer. Meteor. Soc., 59-81.

- 2003: Lee waves and mountain waves. Encyclopedia of Atmospheric Sciences, J. R. Holton, J. Pyle, and J. A. Curry, Eds., Academic Press, 1161-1169 pp.

DuVivier, A. K., and J. J. Cassano, 2013: Evaluation of WRF Model resolution on simulated mesoscale winds and surface fluxes near Greenland. Mon. Wea. Rev., 141, 941-963, doi:10.1175/ MWR-D-12-00091.1.

Eliassen, A., and E. Palm, 1961: On the transfer of energy in stationary mountain waves. Geofys. Publ., 22 (3), 1-23.

Estoque, M., 1961: A theoretical investigation of the sea breeze. Quart. J. Roy. Meteor. Soc., 87, 136-146, doi:10.1002/qj.49708737203.

Fritts, D. C., and M. J. Alexander, 2003: Gravity wave dynamics and effects in the middle atmosphere. Rev. Geophys., 41, 1003, doi:10.1029/2001RG000106.

Grebmeier, J. M., W. O. Smith Jr., and R. J. Conover, 1995: Biological processes on Arctic continental shelves: Ice-ocean-biotic interactions. Arctic Oceanography: Marginal Ice Zones and Continental Shelves, W. O. Smith and J. M. Grebmeir, Eds., Coastal and Estuarine Studies, Vol. 49, Amer. Geophys. Union, 231-261.

Harden, B. E., I. A. Renfrew, and G. N. Petersen, 2011: A climatology of wintertime barrier winds off southeast Greenland. J. Climate, 24, 4701-4717, doi:10.1175/2011JCLI4113.1.

Heinemann, G., and T. Klein, 2002: Modelling and observations of the katabatic flow dynamics over Greenland. Tellus, $\mathbf{5 4 A}, 542$ 554, doi:10.1034/j.1600-0870.2002.201401.x.

Hong, S.-Y., J. Dudhia, and S.-H. Chen, 2004: A revised approach to ice microphysical processes for the bulk parameterization of clouds and precipitation. Mon. Wea. Rev., 132, 103-120, doi:10.1175/1520-0493(2004)132<0103:ARATIM>2.0.CO;2.

-, Y. Noh, and J. Dudhia, 2006: A new vertical diffusion package with an explicit treatment of entrainment processes. Mon. Wea. Rev., 134, 2318-2341, doi:10.1175/MWR3199.1.

Howat, I. M., J. E. Box, Y. Ahn, A. Herrington, and E. M. McFadden, 2010: Seasonal variability in the dynamics of marine-terminating outlet glaciers in Greenland. J. Glaciol., 56, 601-613, doi:10.3189/002214310793146232.

Janjić, Z., and Coauthors, 2011: WRF NMM Model. User's guide for the NMM core of the Weather Research and Forecast (WRF) modeling system version 3, UCAR Tech. Rep., 5-1-5-58. 
Jiménez, P. A., J. Dudhia, J. F. González-Rouco, J. Navarro, J. P. Montávez, and E. García-Bustamante, 2012: A revised scheme for the WRF surface layer formulation. Mon. Wea. Rev., 140, 898-918, doi:10.1175/MWR-D-11-00056.1.

Jin, Y., S. E. Koch, Y.-L. Lin, F. M. Ralph, and C. Chen, 1996: Numerical simulations of an observed gravity current and gravity waves in an environment characterized by complex stratification and shear. J. Atmos. Sci., 53, 3570-3588, doi:10.1175/ 1520-0469(1996)053<3570:NSOAOG > 2.0.CO;2.

Jungclaus, J. H., H. Haak, M. Latif, and U. Mikolajewicz, 2005: Arctic-North Atlantic interactions and multidecadal variability of the meridional overturning circulation. J. Climate, 18, 4013-4031, doi:10.1175/JCLI3462.1.

Kain, J. S., and J. M. Fritsch, 1990: A one-dimensional entraining/ detraining plume model and its application in convective parameterization. J. Atmos. Sci., 47, 2784-2802, doi:10.1175/ 1520-0469(1990)047<2784:AODEPM>2.0.CO;2.

Klein, T., and G. Heinemann, 2002: Interaction of katabatic winds and mesocyclones near the eastern coast of Greenland. $M e$ teor. Appl., 9, 407-422, doi:10.1017/S1350482702004036.

Lane, T. P., J. D. Doyle, R. D. Sharman, M. A. Shapiro, and C. D. Watson, 2009: Statistics and dynamics of aircraft encounters of turbulence over Greenland. Mon. Wea. Rev., 137, 2687-2702, doi:10.1175/2009MWR2878.1.

Mahrt, L., 1982: Momentum balance of gravity flows. J. Atmos. Sci., 39, 2701-2711, doi:10.1175/1520-0469(1982)039<2701: MBOGF $>2.0 . \mathrm{CO} ; 2$.

Marshall, J., and F. Schott, 1999: Open-ocean convection: Observations, theory, and models. Rev. Geophys., 37, 1-64, doi:10.1029/ 98RG02739.

McFarlane, N., 1987: The effect of orographically excited gravity wave drag on the general circulation of the lower stratosphere and troposphere. J. Atmos. Sci., 44, 1775-1800, doi:10.1175/ 1520-0469(1987)044<1775:TEOOEG > 2.0.CO; 2 .

Mernild, S. H., B. U. Hansen, B. H. Jakobsen, and B. Hasholt, 2008: Climatic conditions at the Mittivakkat Glacier catchment (1994-2006), Ammassalik Island, SE Greenland, and in a 109-year perspective (1898-2006). Geogr. Tidsskr. 108, 51-72, doi:10.1080/00167223.2008.10649574.

Michalakes, J., J. Dudhia, D. Gill, T. Henderson, J. Klemp, W. Skamarock, and W. Wang, 2004: The Weather Research and Forecast Model: Software architecture and performance. Proc. 11th ECMWF Workshop on the Use of High Performance Computing in Meteorology, Reading, United Kingdom, European Centre for Medium Range Weather Forecasts, 29.

Mlawer, E. J., S. J. Taubman, P. D. Brown, M. J. Iacono, and S. A. Clough, 1997: Radiative transfer for inhomogeneous atmospheres: RRTM, a validated correlated-k model for the longwave. J. Geophys. Res., 102, 16 663-16682, doi:10.1029/97JD00237.

Moore, G. W. K., and I. A. Renfrew, 2005: Tip jets and barrier winds: A QuikSCAT climatology of high wind speed events around Greenland. J. Climate, 18, 3713-3725, doi:10.1175/ JCLI3455.1.

,-- , and J. J. Cassano, 2013: Greenland plateau jets. Tellus, 65A, 17468, doi:10.3402/tellusa.v65i0.17468.

Mursch-Radlgruber, E., 1995: Observations of flow structure in a small forested valley system. Theor. Appl. Climatol., 52, 3-17, doi:10.1007/BF00865503.

Oltmanns, M., F. Straneo, G. Moore, and S. Mernild, 2014: Strong downslope wind events in Ammassalik, southeast Greenland. J. Climate, 27, 977-993, doi:10.1175/JCLI-D-13-00067.1.

Orlanski, I., 1975: A rational subdivision of scales for atmospheric processes. Bull. Amer. Meteor. Soc., 56, 527-530.
Parish, T. R., and J. J. Cassano, 2001: Forcing of the wintertime Antarctic boundary layer winds from the NCEP-NCAR global reanalysis. J. Appl. Meteor., 40, 810-821, doi:10.1175/ 1520-0450(2001)040<0810:FOTWAB $>2.0 . C O ; 2$.

- and - 2003: The role of katabatic winds on the Antarctic surface wind regime. Mon. Wea. Rev., 131, 317-333, doi:10.1175/ 1520-0493(2003)131<0317:TROKWO > 2.0.CO;2.

Petersen, G. N., I. A. Renfrew, and G. W. K. Moore, 2009: An overview of barrier winds off southeastern Greenland during the Greenland Flow Distortion experiment. Quart. J. Roy. Meteor. Soc., 135, 1950-1967, doi:10.1002/qj.455.

Pickart, R. S., F. Straneo, and G. W. K. Moore, 2003: Is Labrador Sea water formed in the Irminger basin? Deep-Sea Res. I, 50, 23-52, doi:10.1016/S0967-0637(02)00134-6.

Poulos, G. S., J. E. Bossert, T. B. McKee, and R. A. Pielke, 2000: The interaction of katabatic flow and mountain waves. Part I: Observations and idealized simulations. J. Atmos. Sci., 57, 1919-1936, doi:10.1175/1520-0469(2000)057<1919:TIOKFA>2.0.CO;2.

,,,--- and -2007 : The interaction of katabatic flow and mountain waves. Part II: Case study analysis and conceptual model. J. Atmos. Sci., 64, 1857-1879, doi:10.1175/ JAS3926.1.

Ralph, F. M., P. J. Neiman, and D. Levinson, 1997: Lidar observations of a breaking mountain wave associated with extreme turbulence. Geophys. Res. Lett., 24, 663-666, doi:10.1029/ 97GL00349.

Rasmussen, L., 1989: Greenland winds and satellite imagery. VEJRET, N. W. Nilsen, Ed., Danish Meteorological Society, 32-37.

Reinecke, P. A., and D. Durran, 2009: The overamplification of gravity waves in numerical solutions to flow over topography. Mon. Wea. Rev., 137, 1533-1549, doi:10.1175/2008MWR2630.1.

Renfrew, I. A., and Coauthors, 2008: The Greenland flow distortion experiment. Bull. Amer. Meteor. Soc., 89, 1307-1324, doi:10.1175/2008BAMS2508.1.

—, G. N. Petersen, D. A. J. Sproson, G. W. K. Moore, H. Adiwidjaja, S. Zhang, and R. North, 2009: A comparison of aircraft-based surface-layer observations over Denmark Strait and the Irminger Sea with meteorological analyses and QuikSCAT winds. Quart.J. Roy. Meteor. Soc., 135, 2046-2066, doi:10.1002/qj.444.

Ricciardulli, L., and F. Wentz, 2011: Reprocessed QuikSCAT (v04) wind vectors with $\mathrm{Ku}-2011$ geophysical model function. Remote Sensing Systems Tech. Rep. 043011, 8 pp. [Available online at http://images.remss.com/qscat/qscat_Ku2011_tech_report.pdf.]

Sabine, C. L., and Coauthors, 2004: The oceanic sink for anthropogenic $\mathrm{CO}_{2}$. Science, 305, 367-371, doi:10.1126/science.1097403.

Scorer, R., 1967: Causes and consequences of standing waves. Proc. Symp. on Mountain Meteorology, Fort Collins, CO, Department of Atmospheric Science, Colorado State University, 75-102.

Simpson, J. E., 1994: Sea Breeze and Local Winds. Cambridge University Press, $234 \mathrm{pp}$.

Skamarock, W., 2004: Evaluating mesoscale NWP models using kinetic energy spectra. Mon. Wea. Rev., 132, 3019-3032, doi:10.1175/ MWR2830.1.

- , and Coauthors, 2008: A description of the Advanced Research WRF version 3. NCAR Tech. Note NCAR/TN475+STR, 113 pp.

Smith, R. B., 1985: On severe downslope winds. J. Atmos. Sci., 42, 2597 2603, doi:10.1175/1520-0469(1985)042<2597:OSDW>2.0.CO;2.

Stouffer, R. J., and Coauthors, 2006: Investigating the causes of the response of the thermohaline circulation to past and future climate changes. J. Climate, 19, 1365-1387, doi:10.1175/ JCLI3689.1. 
Ulrich, W., 1991: A comparison between hydrostatic and nonhydrostatic simulations of gravity currents and their interaction with orography. Meteor. Atmos. Phys., 46, 1-13, doi:10.1007/BF01026619.

Vage, K., 2010: Circulation and convection in the Irminger Sea. Ph. D. dissertation, Massachusetts Institute of Technology and Woods Hole Oceanographic Institution, 150 pp. [Available online at http://www.dtic.mil/dtic/tr/fulltext/u2/a514561.pdf.]

van Angelen, J. H., M. R. van den Broeke, and W. J. van de Berg, 2011: Momentum budget of the atmospheric boundary layer over the Greenland ice sheet and its surrounding seas. J. Geophys. Res., 116, D10101, doi:10.1029/2010JD015485.

Van den Broeke, M. R., N. P. M. Van Lipzig, and E. Van Meijgaard, 2002: Momentum budget of the East Antarctic atmospheric boundary layer: Results of a regional climate model. J. Atmos. Sci., 59, 3117-3129, doi:10.1175/1520-0469(2002)059<3117: MBOTEA $>2.0 . \mathrm{CO} ; 2$.

Vellinga, M., and R. A. Wood, 2002: Global climatic impacts of a collapse of the Atlantic thermohaline circulation. Climatic Change, 54, 251-267, doi:10.1023/A:1016168827653.

Walter, J. I., E. Jason, S. Tulaczyk, E. E. Brodsky, I. M. Howat, A. H. N. Yushin, and A. Brown, 2012: Oceanic mechanical forcing of a marine-terminating Greenland glacier. Ann. Glaciol., 53, 181-192, doi:10.3189/2012AoG60A083.

Zhang, Y., D. J. Seidel, J.-C. Golaz, C. Deser, and R. A. Tomas, 2011: Climatological characteristics of Arctic and Antarctic surface-based inversions. J. Climate, 24, 5167-5186, doi:10.1175/ 2011JCLI4004.1. 